\title{
Interdecadal Variation of Winter Cold Surge Path in East Asia and Its Relationship with Arctic Sea Ice
}

\author{
Xiaoye Yang, Gang Zeng, Guwei Zhang, and ZhongXian Li \\ Key Laboratory of Meteorological Disaster of Ministry of Education, Collaborative Innovation Center on Forecast and \\ Evaluation of Meteorological Disasters, Nanjing University of Information Science and Technology, Nanjing, China
}

(Manuscript received 8 October 2019, in final form 8 March 2020)

\begin{abstract}
The paths of winter cold surge (CS) events in East Asia (EA) from 1979 to 2017 are tracked by the Flexible Particle (FLEXPART) model using ERA-Interim daily datasets, and the probability density distribution of the paths is calculated by the kernel density estimation (KDE) method. The results showed that the paths of CSs are significantly correlated with the intensity of the CSs, which shows an interdecadal transition from weak to strong around 1995. CS paths can be classified into two types, namely, the western path type and the northern path type, which were more likely to occur before and after 1995, respectively. Before 1995, the cold air mainly originated from Europe and moved from west to east, and the synoptic features were associated with the zonal wave train. After 1995, cold air accumulated over western Siberia and then invaded EA along the northern path, and the synoptic features were mainly associated with the blocking structure. The geopotential height $(\mathrm{GPH})$ anomalies over the Arctic were abnormally strong. This paper further analyzes the relationship between CSs and winter sea ice concentration (SIC) in the Arctic. The results show that the intensity of CSs is negatively correlated with the Barents SIC (BSIC). When the BSIC declines, the upward wave flux over the Barents Sea is enhanced and expanded to the midlatitude region. GPH anomalies over the Arctic are positive and form a negative AO-like pattern, which is conducive to the formation of the northern path CS. Furthermore, the observed results are supported by numerical experiments with the NCAR Community Atmosphere Model, version 5.3 (CAM5.3).
\end{abstract}

\section{Introduction}

Cold surges (CSs) are the main severe weather events that affect East Asia (EA) during the winter half-year, and they are considered to be one of the most striking features of the EA winter monsoon and cause dramatic temperature declines, freezing precipitation, and even snowstorms (Chan and Li 2004; Yang et al. 2010). An active CS usually occurs with a strong Siberian high. The cold advection generated by the Siberian high strengthens the north component of low-level winds, thus resulting in a CS (Ding 1990; Zhang et al. 1997). Many studies have different definitions for a CS. Ryoo et al. (2005) defined a CS as an event where the minimum temperature dropped by more than $7.5 \mathrm{~K}$ in 2 days. Studies have also used both temperature declines and the Siberian high as criteria for defining a CS (Zhang et al. 1997; Chen et al. 2004; Jeong and Ho 2005). Considering the problems with these methods, Park et al. (2011a,b) and Park and Deng (2013) used the

\footnotetext{
Corresponding author: Gang Zeng, zenggang@nuist.edu.cn
}

Siberian high, daily temperature declines, and negative temperature anomalies [surface air temperature (SAT) minus the mean SAT of every year on this day] to define a CS. As early as 1955, Li (1955) classified the CS events in EA into three types. The cold air of the first type crosses China and eventually enters the Pacific Ocean, the second type mainly affects central and northern China, and the last type of CS moves southward along the coast of EA. However, due to the small number of CS samples and data methods, Li studied three paths of CS invading China from central Siberia but did not analyze the complete CS path in Eurasia. Through the clustering analysis of the circulation before the outbreak of a CS, Park and Deng (2013) further classified CS events of EA into wave train and blocking types and then discussed the synoptic and dynamic differences between the two types. The frequency and intensity of CS events are important elements in describing CS activity, and these variables affect climate change and have more direct impacts on social and ecological systems.

Due to the intensification of global warming and the weakening of EA winter monsoon, some studies have 
indicated that the frequency of CSs will decline in EA (Gao et al. 2002; Alexander et al. 2006; Wang and Ding 2006; IPCC 2007, 2013). However, some scholars believe that the process of a CS event is not only represented by a simple temperature change but also includes a circulation evolution associated with planetary wave activity (Chen et al. 2005). The frequency and intensity of CS events will remain or be enhanced in the long term (Jeong and Ho 2005; Choi et al. 2009; Park et al. 2011b). As one of the main characteristics of the CS, its path has been a popular research topic in recent years. Tao (1957) found that the cold air that caused the CS in EA mainly came from the Barents-Kara Sea, and Ding (1990) further confirmed that the Atlantic Ocean south of Iceland is also one of the sources of cold air. Previous studies have identified a CS path using cold high-pressure centers or 24-h surface air temperature drop centers. In recent years, the trajectory analysis method based on the Lagrangian framework has provided a proper technical method of studying CS paths. Walsh et al. (2001) tracked the paths of strong cold air affecting the eastern United States and northwestern Europe using the reverse method. Park et al. (2011a) used the Flexible Trajectory model (FLEXTRA) to analyze the relationship between the CS path and the Arctic Oscillation (AO) phase. The Hybrid Single Particle Lagrangian Integrated Trajectory Model (HYSPLIT) was used by Cai et al. (2019) to study the different types of cold wave paths and their atmospheric circulation characteristics in autumn in North China. These studies demonstrate the feasibility of applying the Lagrangian method to the study of CS paths. The results show that CS events with different paths have different circulation characteristics and bring different weather phenomena to EA.

In addition to the studies of the characteristics of the CS itself, many studies on CSs have mainly focused on the large-scale circulation condition and the influence of sea surface temperature (SST) anomalies, such as El Niño-Southern Oscillation (ENSO) and AO (Chen 2002; Chen et al. 2004; Jeong and Ho 2005; Park et al. 2011a). However, there is still a lack of detailed research on how Arctic sea ice affects CS events in EA. In the past two decades, with continuous global warming and Arctic sea ice decreases, the amplification effect of the Arctic on global warming has become increasingly prominent (Screen and Simmonds 2010), and this effect strengthens the connection between the polar and the middle to low latitudes and increases the intraseasonal and interannual variability of atmospheric circulation (Zhao et al. 2004; Li and Wang 2012; Gao et al. 2014; Wu et al. 1999, 2013, 2016; Wu 2017; Fan et al. 2018; Ji and Fan 2019), which is conducive to the occurrence of extreme weather events (Wang et al. 2015; Wu 2017). Arctic sea ice is a cold source and plays a role in stabilizing ocean stratification in the climate system. Sea ice changes strongly affect the effective absorption of solar radiation energy by changing the albedo. Sea ice blocks or isolates the exchange of heat, momentum, and matter between sea and air. Meanwhile, since sea ice is closely related to freshwater circulation and ocean stratification, sea ice change may affect the deep-water circulation of the ocean and the long-term trend of climate change (Thorndike and Colony 1982; Makshtas and Andreas 1991; Proshutinsky and Johnson 1997; Serreze et al. 2007; Ogi et al. 2010; Screen and Simmonds 2010). The melting of Arctic sea ice means that the role of the Arctic cold source is weakening. Since the late 1990s, Arctic sea ice has experienced a rapid melting trend. The abnormal decrease of Arctic sea ice is consistent with the changes in the cold winter of Eurasia (Honda et al. 2009; Petoukhov and Semenov 2010; Inoue et al. 2012; Liu et al. 2012; Dai et al. 2019). However, whether the melting of sea ice is the main cause of the cold winter in Eurasia, the mechanism is still controversial (Blackport et al. 2019; Blackport and Screen 2019; Mori et al. 2019b; Screen and Blackport 2019b). Some studies have indicated that the loss of sea ice, particularly in the Barents Sea, can weaken the polar vortex and strengthen the Siberian high and Ural blocking high, which provides favorable conditions for the formation of blocking circulation (Inoue et al. 2012; Kim et al. 2014; Luo et al. 2018) and increases the probability of extreme cold events (Francis and Vavrus 2012; Barnes and Screen 2015). However, there is no consensus on this view (McCusker et al. 2016; Sun et al. 2016; Ogawa et al. 2018). Global warming increases the average temperature in winter, while sea ice melting strengthens the winter blocking circulation in Eurasia, which facilitates the southward movement of cold air in the Arctic region. Predicting the change of CSs in the future remains challenging.

Many earlier studies focused on the occurrence of CSs in EA (Ding 1990; Chen et al. 2004; Jeong and Ho 2005; Choi et al. 2009; Park and Deng 2013; Heo et al. 2018), although few studies have focused on the paths of CSs from the perspective of climatology, especially its decadal variability. How have changes in the CS paths affected EA from 1979 to 2017? Is this change related to Arctic sea ice? If so, what is the possible mechanism of the Arctic sea ice influence on CSs in EA? This study focuses on these questions and will help understand the variability of the CS path in EA and its possible cause. To obtain more reliable results, we used the FLEXPART model to track the CS path and then used numerical simulations to verify the relationship between path and Arctic sea ice. 
This paper is organized as follows. Section 2 describes the datasets and the mathematical and modeling methods used in this paper. Section 3 introduces the interdecadal variation in the CS path and its circulation characteristics. Section 4 discusses the relationship between the path change and Arctic sea ice. Section 5 describes numerical simulations by the Community Atmosphere Model, version 5.3 (CAM5.3) to verify the previous conclusions. Finally, conclusions and discussion are presented in section 6 .

\section{Data and methods}

\section{a. Data}

To calculate the frequency and intensity of CS events and analyze their synoptic and dynamic features, we used the ERA-Interim daily datasets (Dee et al. 2011) provided by the European Centre for Medium-Range Weather Forecasts (ECMWF). These data have a $2.5^{\circ} \times 2.5^{\circ}$ horizontal resolution and 37 vertical pressure levels ranging from 1000 to $1 \mathrm{hPa}$. The dataset includes the sea level pressure (SLP), temperature, horizontal wind, and potential height. Six-hourly data were used to track the CS paths by FLEXPART, and these data were also obtained from the ERA-Interim dataset. The monthly SIC was obtained from the Hadley Centre (Rayner et al. 2003), and these data have a horizontal resolution of $1^{\circ} \times 1^{\circ}$.

\section{b. Definition of cold surge event}

The criteria for defining a CS event in this study are mainly based on the methodology of Park et al. (2011a,b) and Park and Deng (2013). However, we made some additional improvements. An active CS is often caused by cold advection produced by the Siberian high. Therefore, we first eliminated the cold events caused by the local SAT dropping by considering the central value and position of the Siberian high. When a CS event occurs, the maximum pressure center in the domain of the Siberian high (Fig. 1) should exceed $1035 \mathrm{hPa}$. To avoid the impact of single grid surface temperature anomalies and exclude small-scale cold events, we divided EA into $5^{\circ} \times 5^{\circ}$ grid boxes as shown in Fig. 1 and then calculated the mean SAT for each grid box. There are differences in the sensitivity to cold events between the north and the south. The threshold of the CS standard should be adjusted according to the local climate characteristics. Therefore, when a CS occurs, the daily temperature drop $\left(\mathrm{SAT}_{t}-\mathrm{SAT}_{t-1}\right)$ and the SAT anomalies based on the 39 winters from 1979 to 2017 should exceed $-1.5 \sigma$ ( $\sigma$ is the standard deviation of the SAT during the 39 winters). A CS event is defined as when

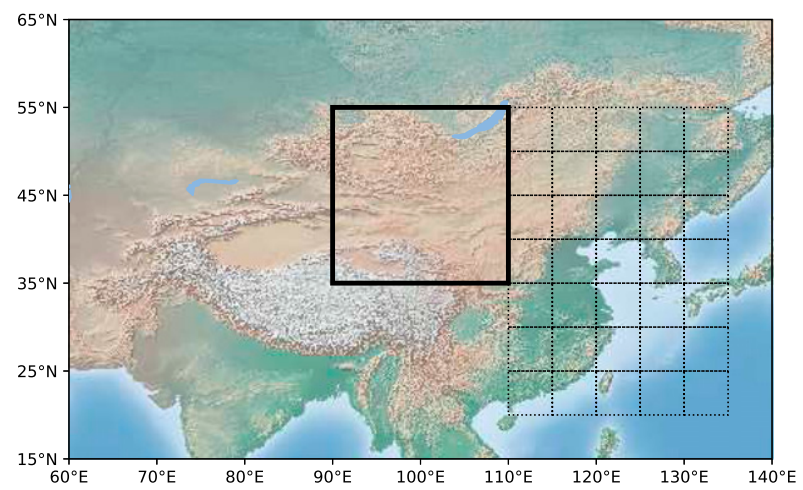

FIG. 1. Domain of the Siberian high (thick solid box; $35^{\circ}-55^{\circ} \mathrm{N}$, $90^{\circ}-115^{\circ} \mathrm{E}$ ) and East Asia (dotted box; $20^{\circ}-55^{\circ} \mathrm{N}, 110^{\circ}-135^{\circ} \mathrm{E}$ ) divided into $5^{\circ} \times 5^{\circ}$ grid boxes.

one or more boxes in EA meet the criteria above. Based on these criteria, we screened 409 CS events in 39 winters from 1979 to 2017 (winter here is defined as December of one year to February of the following year). Finally, continuous CS events need to be eliminated. Here, we follow the method of Heo et al. (2018). The end date of a CS is defined as the first day in which the daily SAT anomaly rise exceeds $-0.5 \sigma$ after a CS event occurs. Based on all the conditions above, 108 continuous CS events were eliminated and 301 CS events were ultimately identified. The intensity of each CS event is defined as the mean value of the daily SAT decline from the beginning to the end of a CS event. We focus on the daily cooling of the CS process rather than the total cooling by this definition. Therefore, differences with previous studies may occur (Woo et al. 2012; Heo et al. 2018).

\section{c. CS trajectory tracking}

Park et al. (2011a) used the FLEXTRA model to track the CSs of EA under positive and negative AO phases. The FLEXPART model (Pisso et al. 2019) is a further development of its predecessor FLEXTRA. It is a Lagrangian particle diffusion model that is suitable for simulating a large range of atmospheric transport processes. In this study, we used FLEXPART to track the CS path as follows. On the first day of each CS event, we start from the box where the CS occurs (when a CS occurs in more than one box, the box with the largest temperature drop is selected), release 10000 particles (the physical and chemical characteristics of the particles are equivalent to air tracers) at 0000, 0600,1200, and 1800 UTC and at the pressure levels ranging from 850 to $500 \mathrm{hPa}$, respectively, to perform a backward simulation for $120 \mathrm{~h}$. The release height and time are set so that they are consistent with the characteristics of CS development and avoid the influence of topography (Ding 1990; Chan and Li 2004). Based on the principle of 
FLEXPART, the particle's trajectory equation is as follows:

$$
\frac{d \mathbf{X}(t)}{d t}=\dot{\mathbf{X}}[X(t), t]
$$

where $t$ is the time, $\mathbf{X}$ is the position vector, and $\dot{\mathbf{X}}$ is the wind velocity vector. To solve Eq. (1), Stohl (1998) used the "constant acceleration" scheme. Then, we obtain the following results:

$$
\mathbf{X}\left(t_{1}\right) \approx \mathbf{X}\left(t_{0}\right)+\frac{1}{2}(\Delta t)\left[\dot{\mathbf{X}}\left(t_{0}\right)+\dot{\mathbf{X}}\left(t_{1}\right)\right],
$$

where $\Delta t$ represents the time interval. We can solve Eq. (2) by iteration:

$$
\begin{aligned}
& \mathbf{X}^{1}\left(t_{1}\right) \approx \mathbf{X}\left(t_{0}\right)+(\Delta t) \dot{\mathbf{X}}\left(t_{0}\right), \\
& \mathbf{X}^{2}\left(t_{1}\right) \approx \mathbf{X}\left(t_{0}\right)+\frac{1}{2}(\Delta t)\left[\dot{\mathbf{X}}\left(t_{0}\right)+\dot{\mathbf{X}}^{1}\left(t_{1}\right)\right], \\
& \mathbf{X}^{i}\left(t_{1}\right) \approx \mathbf{X}\left(t_{0}\right)+\frac{1}{2}(\Delta t)\left[\dot{\mathbf{X}}\left(t_{0}\right)+\dot{\mathbf{X}}^{i-1}\left(t_{1}\right)\right] .
\end{aligned}
$$

The superscripts indicate the number of iterations in Eq. (3). When the difference between the right two iterations of the equation is less than a certain value, the iteration is ended and the particle trajectory is determined. More information about the FLEXPART model can be found on the official website (https:// www.flexpart.eu/).

\section{d. Kernel density estimation}

Kernel density estimation (KDE) is one of the most effective nonparametric density estimation methods proposed by Rosenblatt (1956) and Parzen (1962). KDE needs no prior information on the data distribution and does not attach any assumptions to the data distribution. In KDE, the estimated value of the true state of the sampling point is the average superposition of all the kernel functions centered at the point. Thus, KDE can estimate the case where the density function is a multimodal distribution. Suppose that $x_{1}, x_{2}, \ldots, x_{n}$ are random variables with independent identical distributions, and they obey the distribution density function $f(x), x \in R$. We define the following functions:

$$
\hat{f}_{h^{(x)}}=\frac{1}{n h} \sum_{i=1}^{n} K\left(\frac{x_{i}-x}{h}\right), \quad x \in R .
$$

This process is called the KDE of the density function $f(x)$, where $K$ is the kernel function, and $h$ is a predetermined positive number generally called the bandwidth. The $\operatorname{KDE}\left(\hat{f}_{h^{(x)}}\right)$ of the distribution density function $f(x)$ is related not only to a given set of samples but also to the selection of the kernel function and the selection of the bandwidth. To achieve nonlinear mapping and reduce the difficulty of numerical calculation, we chose the Gaussian kernel function in this study.

\section{e. Wave activity flux}

The wave activity flux can be used to diagnose the propagation of Rossby waves. Plumb (1985) uses the conservation relationship of small-amplitude steady wave propagation in a uniform zonal flow and gives the three-dimensional wave activity flux of the stationary Rossby wave to characterize the wave energy and the direction of the propagation. The three-dimensional wave flux diagnostic equation of Plumb's wave activity flux in spherical coordinates can be expressed as follows:

$$
F_{s}=\frac{p}{p_{0}} \cos \varphi \times\left\{\begin{array}{c}
v^{\prime 2}-\frac{1}{2 \Omega \sin 2 \varphi} \frac{\partial\left(v^{\prime} \Phi^{\prime}\right)}{\partial \lambda} \\
-u^{\prime} v^{\prime}+\frac{1}{2 \Omega \sin 2 \varphi} \frac{\partial\left(u^{\prime} \Phi^{\prime}\right)}{\partial \lambda} \\
\frac{f}{S}\left[v^{\prime} T^{\prime}-\frac{1}{2 \Omega \sin 2 \varphi} \frac{\partial\left(T^{\prime} \Phi^{\prime}\right)}{\partial \lambda}\right]
\end{array}\right\}
$$

In Eq. (5), $(\varphi, \lambda)$ represents the latitude and longitude, $(a, \Omega)$ is the radius of Earth and Earth's rotation rate, $f=$ $2 \Omega \sin \varphi$ represents the Coriolis parameter, and $(\Phi, T)$ indicates the potential height and temperature. Static stability is represented by $s$, and it is expressed as follows:

$$
s=\frac{\partial \bar{T}}{\partial z}+\frac{\kappa \bar{T}}{H},
$$

where $\kappa \approx 0.286$ is the ratio of the gas constant to the specific heat at constant pressure, and $H=8000 \mathrm{~m}$ is the constant height. The variables in Eqs. (5) and (6) marked with an overbar and a prime represent the zonal mean and zonal deviation, respectively.

\section{f. Numerical model}

CAM5.3 is part of the Community Earth System Model, version 1.2.2 (CESM1.2.2), modeling framework. CAM is used as both a standalone model and as the atmospheric component of the CESM. CAM has a long history of use as a standalone model by the atmosphere, and it is also coupled to an active land model, a thermodynamic-only sea ice model, and a data ocean model. This model is widely used in climate change research (Zhang et al. 2016; Huang et al. 2019; Mori et al. 2019a; Screen and Blackport 2019), including the study of sea ice loss. The finite-volume dynamical 

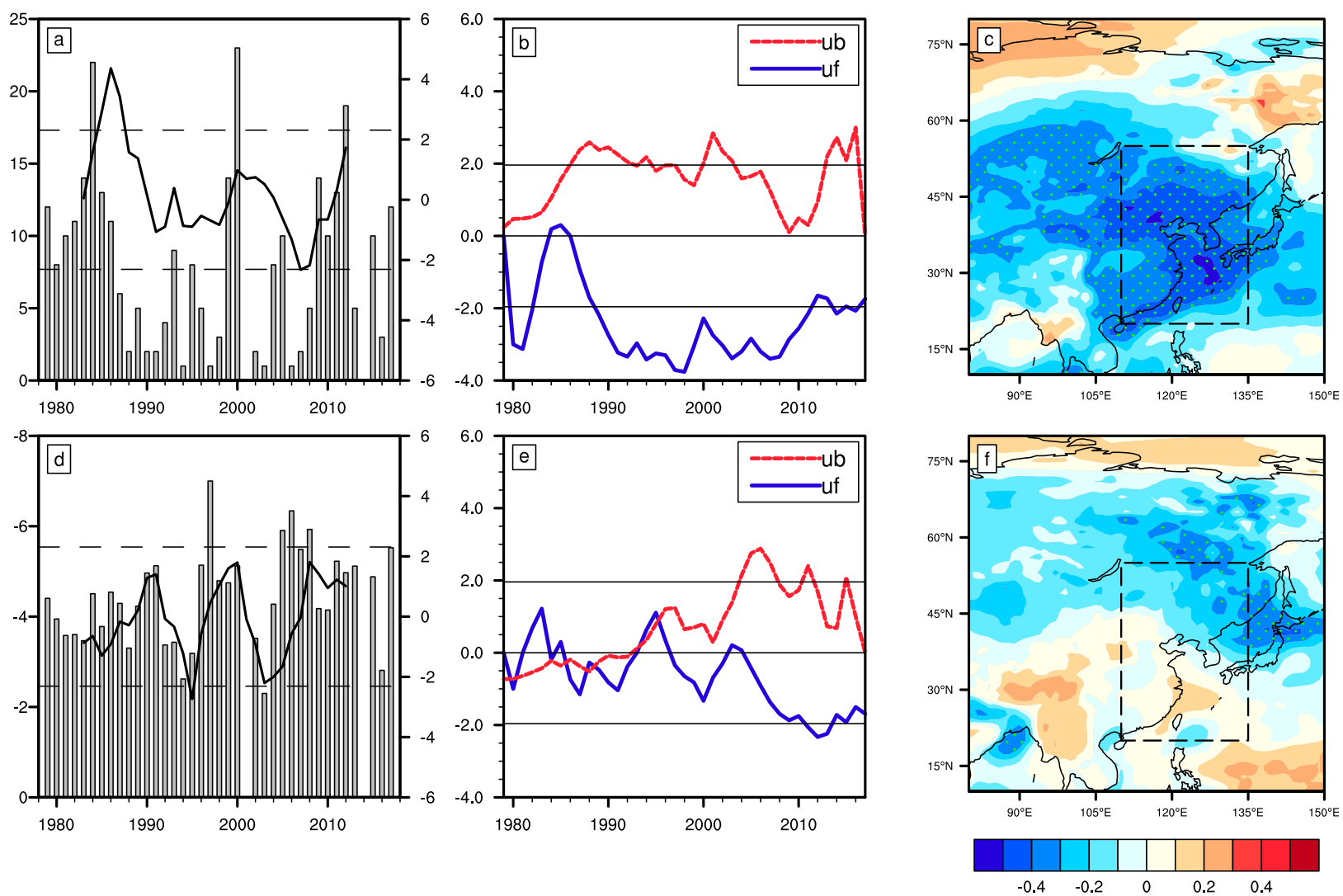

FIG. 2. (a) Frequency and (d) intensity of CS events from 1979 to 2017 and (b),(e) their respective Mann-Kendall tests. (c),(f) Correlation coefficients between the winter mean SATs and CS frequency and CS intensity, respectively. Solid lines in (a) and (d) represents the sliding $t$ test of the CS frequency and CS intensity, and the dashed lines in (a) represent the $95 \%$ confidence level of the sliding $t$ test. The boxes in (c) and (f) represent the region of East Asia.

core configured with a horizontal resolution of $1.9^{\circ}$ latitude $\times 2.5^{\circ}$ longitude (f19_f19) and 30 vertical hybrid levels are selected. More details about the model can be found in Neale et al. (2012).

\section{Interdecadal variations in winter CS in EA}

According to the definition of CS in section $2 b$, we calculated the frequency and intensity of CS events in the 39 winters from 1979/80 to 2017/18 (Figs. 2a,d). In total, $301 \mathrm{CS}$ events were identified in this study. The frequency of CS identified by our statistics is consistent with that of the previous studies (Wang and Ding 2006; Park et al. 2011b; Heo et al. 2018), while the intensity of $\mathrm{CS}$ is different due to the different research regions and the definitions of intensity. CS events occurred more frequently before the mid-1980s and after the mid-2000s. This pattern is related to the intensity of the East Asian winter monsoon and AO, which strongly affects the Siberian high (Wu and Wang 2002; Wang and Ding 2006; Park et al. 2011a; Heo et al. 2018). The intensity of CS events exhibited an interdecadal variation that transitioned from weak to strong in 1995. The interdecadal variations of CS intensity passed the significance test with $95 \%$ confidence based on the sliding $t$ test. We also used the Mann-Kendall test to verify this variation (Fig. 2e). The linear trend of CS intensity is not statistically significant. The interdecadal variation around 1995 is a mutation. Although there were still two years of low CS intensity in the early 2000s, the frequency of CS in these two years was very low and was not statistically significant in the trend test, so we still used 1995 as the interval point to compare the two periods. The correlation coefficients between the winter mean SAT and the frequency (the intensity) of the CS events are shown in Fig. 2c (Fig. 2f). A significant negative correlation between the winter mean SAT and the occurrence of CS events can be found in almost all of EA, with a maximum that exceeded -0.5 in central Inner Mongolia and the East China Sea. These conclusions can be confirmed by previous studies (Wang and Ding 2006; Heo et al. 2018). However, the negative response of the winter mean SAT to the CS intensity is mainly shown in the northern region of EA. 

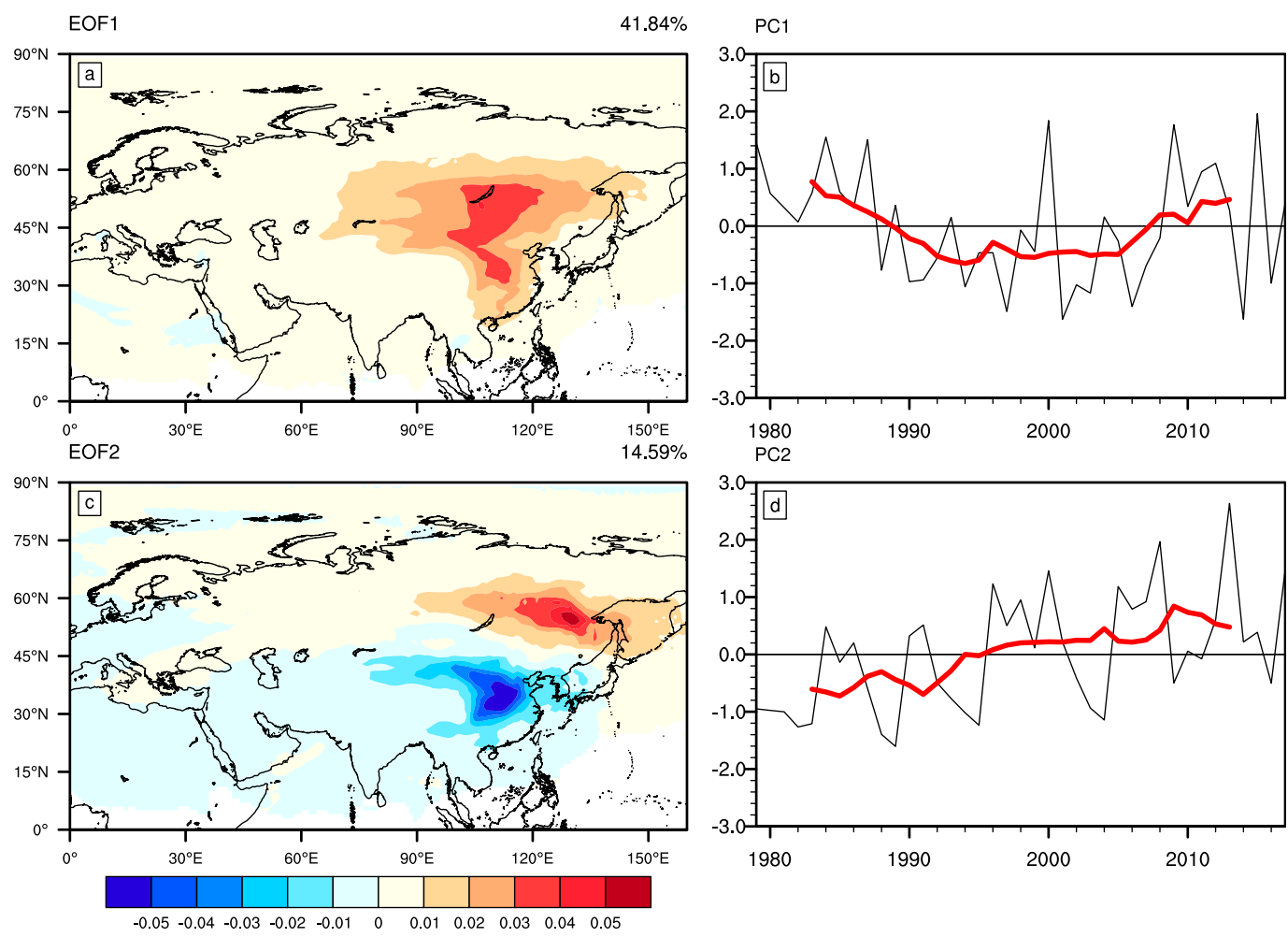

FIG. 3. (a),(c) First two EOFs of the probability density distribution of the CS paths in East Asia in winter from 1979 to 2017 and (b),(d) their corresponding standardized PC series. The percentage of explained variance is given in the top-right corner of (a) and (c). The red solid lines (b) and (d) are the 9-yr moving average of the PC series.

The paths of 301 CS events are tracked by FLEXPART, and then KDE is used to calculate the particle distribution of each CS path into the probability density distribution, which can be regarded as the density distribution of cold air activity when the CS events occur. Then, we composite the probability density distribution of CS events each year and obtain the two main patterns and their principal component (PC) series (Fig. 3) using the empirical orthogonal function (EOF) analysis [also known as principal component analysis (PCA), which was first introduced in geophysics by Lorenz (1956)]. The correlation coefficient between $\mathrm{PC} 1$ and the occurrence series of CS events is 0.76 and that between PC2 and the intensity of CS events is 0.73 , which both achieve a confidence level of $99 \%$. Therefore, the first mode of EOFs (EOF1) can well reflect the climatic state of the CS path distribution. The density distribution of CS events is centered on EA and extends to the north and west, and it covers most parts of Siberia. In high PC1 years, CSs occur more frequently. The maximal center is located in the key region of cold air near Lake Baikal (Ding 1990; Cai et al. 2019). EOF2 reflects two different types of CS event paths. When PC2 is high, the CS events in that year are dominated by the northern paths, which mainly affect the northern region of EA; in contrast, when PC2 is low, the CS events are dominated by western paths, which affect the central and southern regions of EA. This result agrees with the conclusion drawn in Fig. 2d: when the intensity of a CS event is relatively strong, only the winter mean SAT of the northern EA is obviously lower than usual.

As mentioned above, the intensity of CS events has an interdecadal transition from weak to strong in 1995. Correspondingly, a pattern transformation also occurred in relation to the paths of CS events in 1995 (Fig. 4). During the period from 1979 to 1995, the center of cold air mainly passed through Kazakhstan and invaded the central EA by a western path. After 1995, northern path CS events began to dominate. The probability density of cold air in northeast Siberia increased significantly, especially in eastern parts of Baikal. The paths of CS events have a strong correspondence with the intensity of the CS, indicating that the cold air that invaded into EA from the north is stronger than that from the west (Tao 1957).

Park and Deng (2013) divided the CS events in EA into wave train CS and blocking CS events using the clustering method. Based on their research, we establish the relationship between the dominant modes of the CS path and the circulation. We composite the atmospheric 

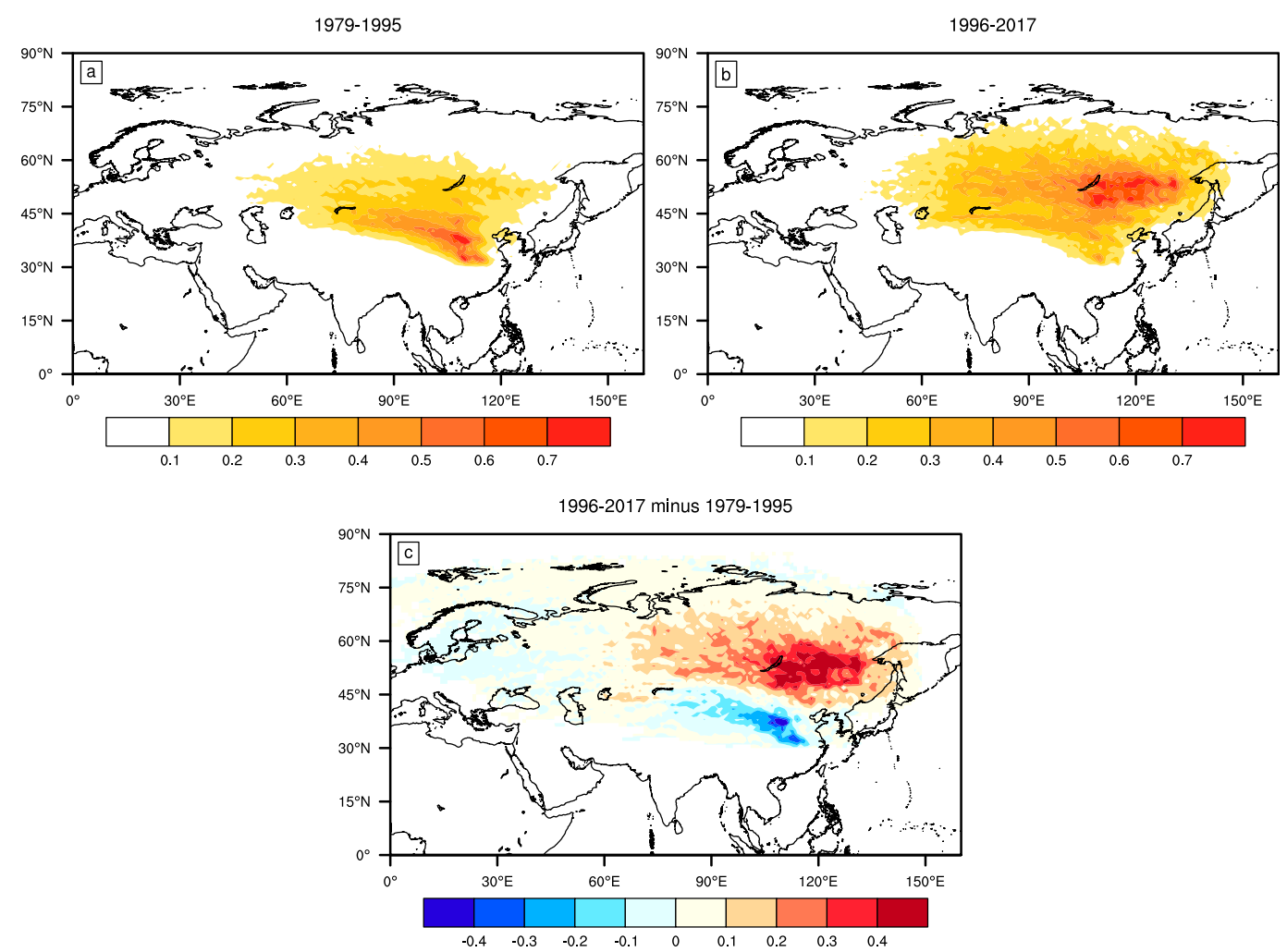

FIG. 4. Probability density distribution of CS paths in East Asia in winter during (a) 1979 to 1995 and (b) 1996 to 2017, and (c) their difference.

circulations of the CS events from 1979 to 1995 and from 1996 to 2017 and then obtain the respective structures. Figure 5 shows the composited circulations from day -4 to day 0 of the CS events in these two periods. For the period from 1979 to 1995 , a zonal wave train structure of geopotential height (GPH) anomalies can be seen in the midlatitude of the Eurasian continent at $500 \mathrm{hPa}$. The GPH anomalies over the Ural Mountains are positive, which are opposite to those over the EA. From day -4 to day 0 , the positive GPH anomalies over the Ural Mountains gradually strengthen and extend to the southeast, and the negative anomalies over EA become stronger and move to the east. The GPH anomalies at $850 \mathrm{hPa}$ are relatively weak. Negative GPH anomalies form over EA and strengthen slightly with time. Cold air moves from west to east and invades EA along with this zonal wave train, forming the western path of the CS described above. For the period from 1996 to 2017, the GPH anomalies over the Arctic are significantly strong, and the center of the anomalies is relatively east. The negative GPH anomalies over EA are similar to those in the period from 1979 to 1995. These two anomalies resulted in a blocking structure, and the gradient between the positive and negative centers increased as the CS approached.
Under this circulation pattern, the cold air that invaded EA mainly came from the north.

To further analyze the circulation differences between the two periods, their vertical cross sections are shown in Fig. 6. Figures 6a, 6c, and 6e show the zonal vertical sections of the GPH anomalies averaged from $40^{\circ}$ to $60^{\circ} \mathrm{N}$ during the evolution from day -4 to day 0 relative to the CS events that occurred from 1979 to 1995 , and the zonal wave train structure can be seen more clearly. The structure slopes slightly westward with height and has a baroclinic structure. The temperature $(T)$ anomalies of the wave train are opposite at the upper and lower levels. As the wave train moved eastward with time, the negative GPH anomalies over EA strengthened. Compared with the relatively weak baroclinic structures of this period, the GPH anomalies in the middle and high latitudes and the $T$ anomalies in the high latitudes are relatively consistent from low to high levels during the period from 1996 to 2017 shown in Figs. 6b, 6d, and 6f. From day -4 to day 0 , the positive anomalies of GPH and $T$ over high latitudes were gradually strengthened and extended to the south, while the positive anomalies of low latitudes remained stable, making the negative anomalies of GPH and $T$ over EA blocked and 

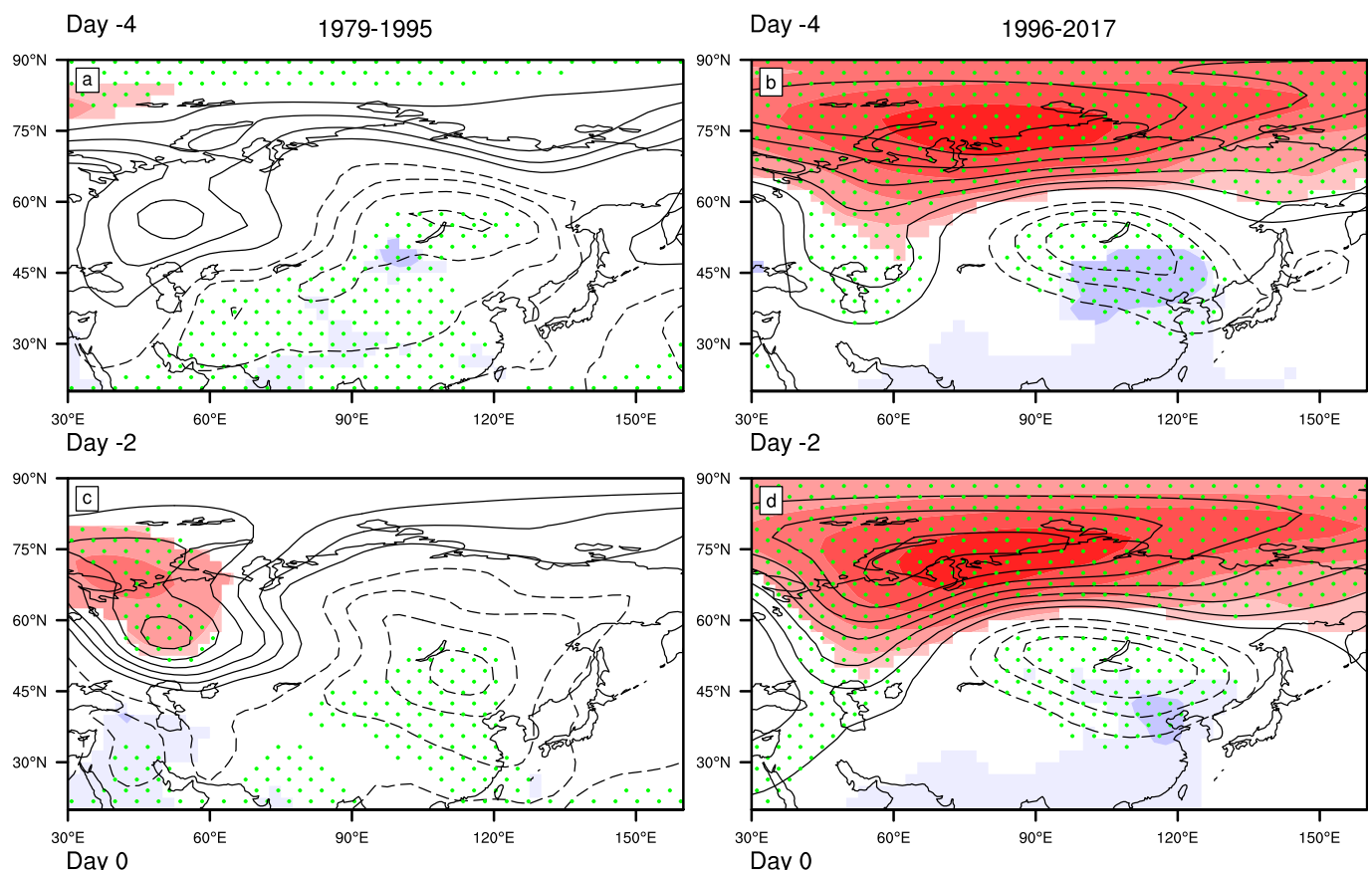

$$
\text { Day -2 }
$$
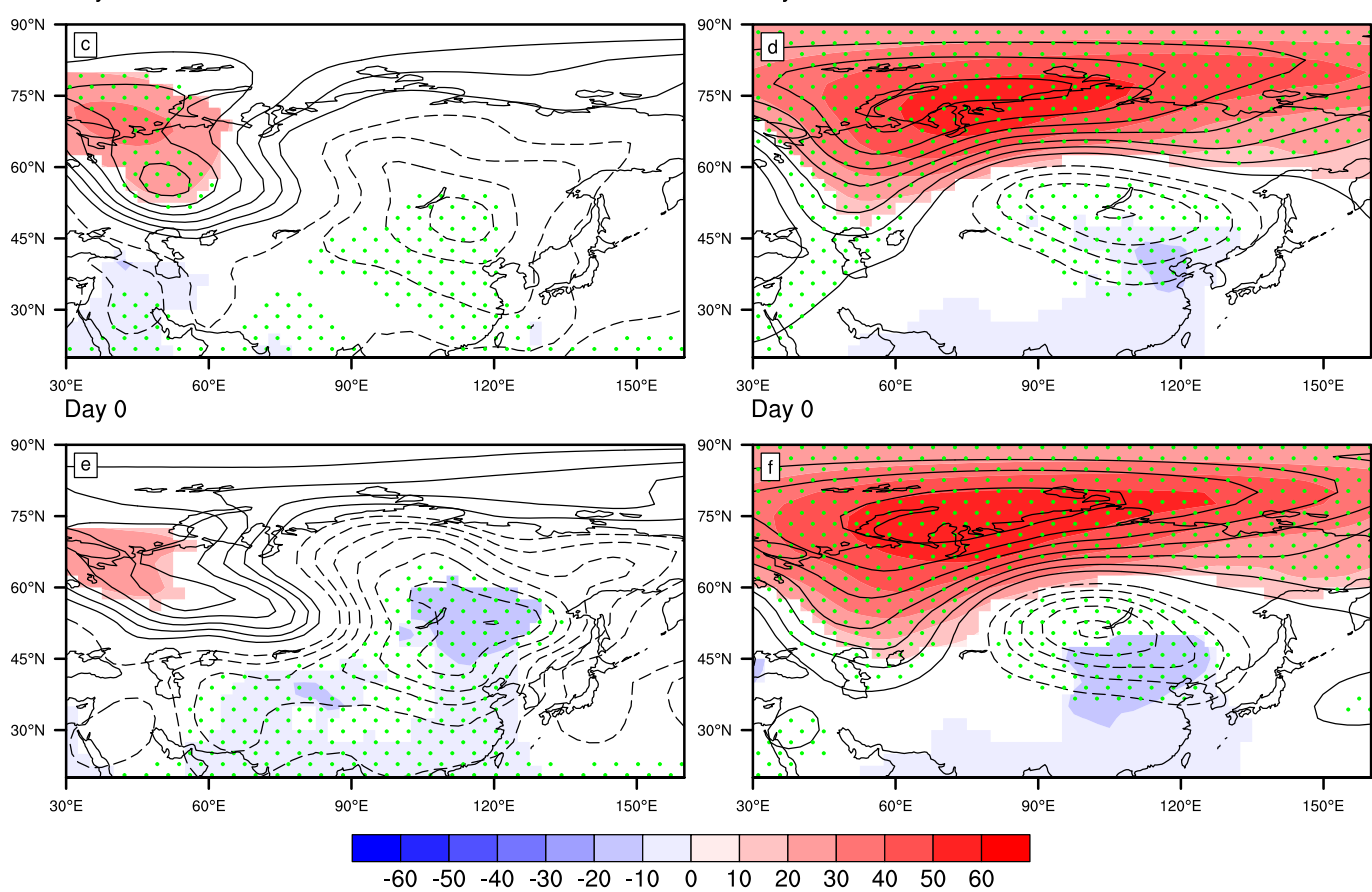

FIG. 5. Composite anomalies of GPH at $500 \mathrm{hPa}$ (contours; solid and dashed lines represent positive and negative, respectively; green dots are significant at the $95 \%$ confidence level) and at $850 \mathrm{hPa}$ (shading; only showing significant values at the $95 \%$ confidence level) for day -4 to day 0 relative to CS events during (a),(c),(e) 1979 to 1995 and (b),(d),(f) 1996 to 2017.

compressed in situ. The stability of the GPH anomalies over the low-latitude region prevents cold air from spreading to the southern part of EA. This pattern is consistent with the results of previous studies (Barnes and Screen 2015; Francis and Vavrus 2012), in which blocking patterns tended to result in a cold winter in North Asia.

The process of CS events is often accompanied by significant abnormal activities in atmospheric long waves and transient waves (Chen et al. 2013; Park and Deng 2013; Shi et al. 2017; Cai et al. 2019). To reflect the timedependent evolution of the Rossby long wave and avoid the influence of the subjective selection of background circulation, Plumb's wave activity flux (WAF) is used to study the dynamic difference in the CS events in the two periods (Fig. 7). In this paper, all fluxes were processed as the composite of anomalies. During the period from 1979 to 1995 , there were global wavetrains at middle and high latitudes at $300 \mathrm{hPa}$. From day -4 to day -2 , the perturbation over the North Atlantic weakened, and the energy was transmitted downstream, resulting in the positive GPH anomalies strengthening over the Ural Mountains. At day 0, the perturbation over the North Atlantic and Europe was no longer significant, and the wave energy continued to spread eastward from the Ural Mountains. The negative GPH anomalies over EA rapidly strengthened and expanded. During the period from 1996 to 2017, the GPH anomalies over the Arctic were exceptionally strong. From day -4 to day 0 , the wave energy was constantly converging over the 

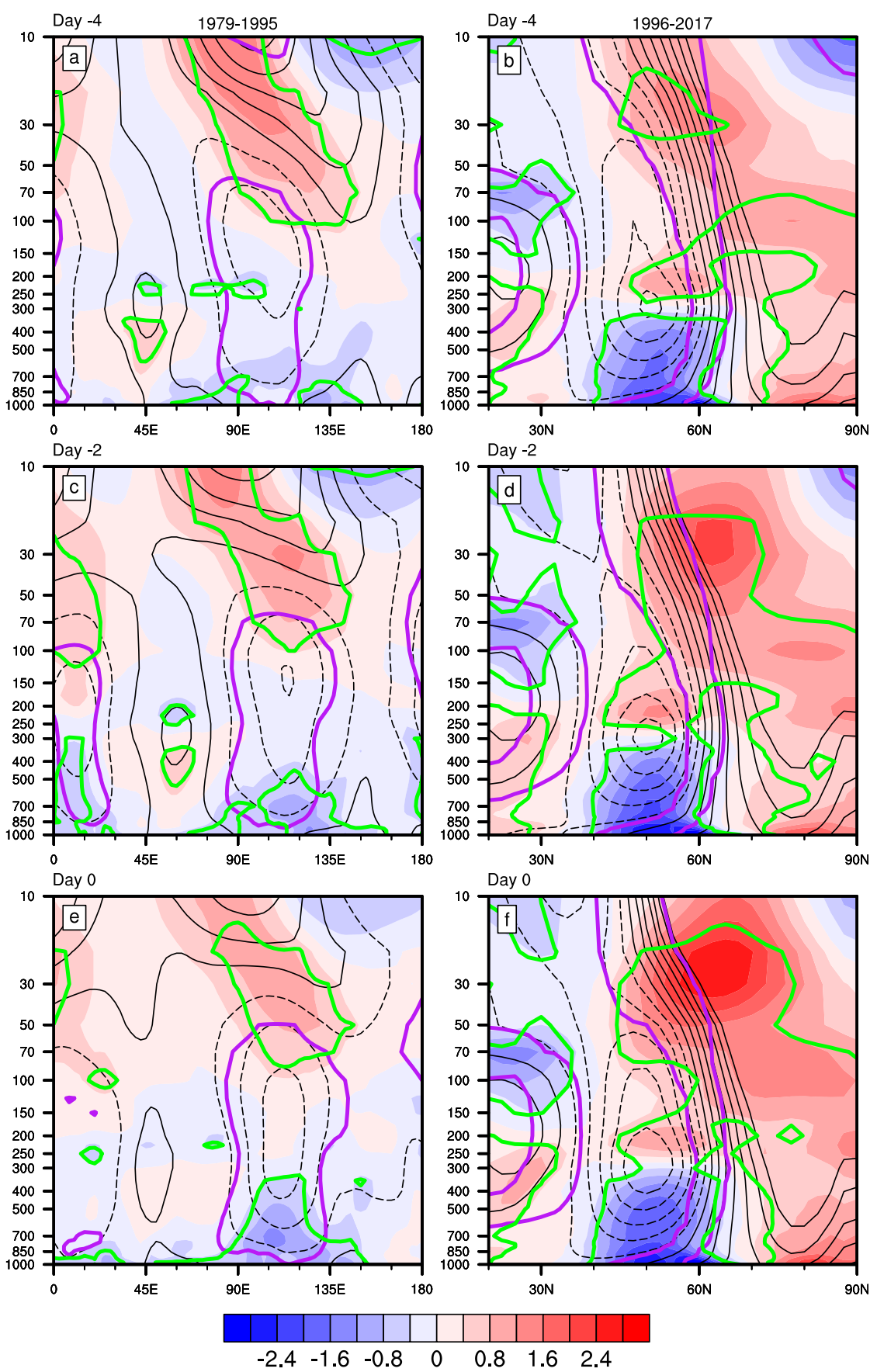

FIG. 6. Vertical cross sections of (a),(c),(e) GPH anomalies averaged from $40^{\circ}$ to $60^{\circ} \mathrm{N}$ (contours; the solid lines represent positive, the dotted lines represent negative, and purple lines represent the significant values at the $95 \%$ confidence level) and $T$ anomalies (shading; green lines represent the significant values at the $95 \%$ confidence level) for day -4 to day 0 relative to CS events during 1979 to 1995 and (b),(d),(f) the anomalies at $120^{\circ} \mathrm{E}$ during 1996 to 2017.

Norwegian Sea and the Ural Mountains. As a result, the negative GPH anomalies over the Norwegian Sea were maintained. The positive anomalies over the Ural Mountains and the Arctic were continuously strengthened and then extended to the southeast, and the wave energy from the northwestern and northern regions converged in EA, which was caused by the strengthened negative GPH anomalies. The comparison 

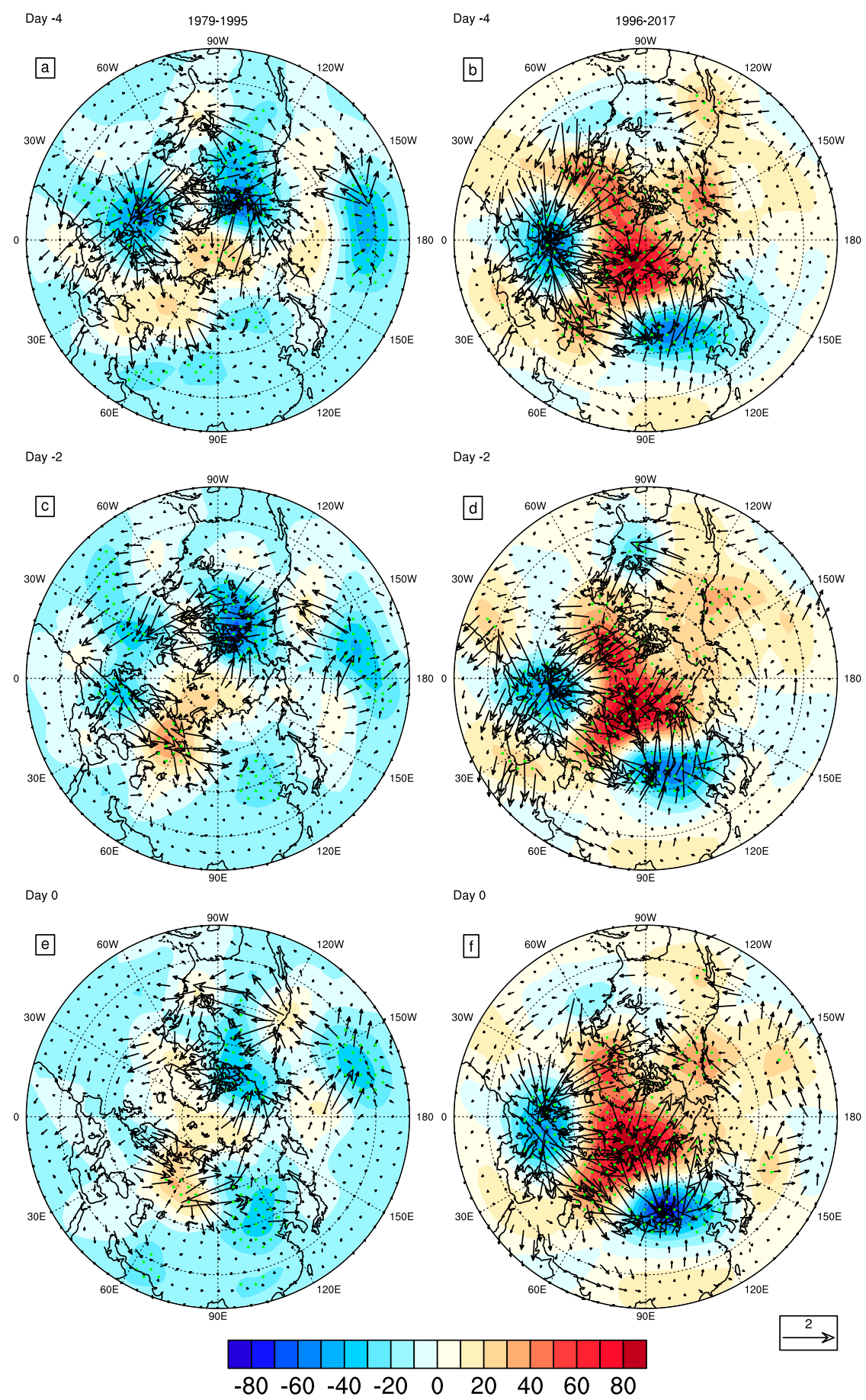

FIG. 7. Composite anomalies of GPH at $300 \mathrm{hPa}$ (shading; green dots are significant at the 95\% confidence level) and horizontal component anomalies of Plumb's wave activity flux (vectors; $\mathrm{m}^{2} \mathrm{~s}^{-2}$ ) for day -4 to day 0 relative to CS events during (a),(c),(e) 1979 to 1995 and (b),(d),(f) 1996 to 2017.

shows that the wave activity and the GPH anomalies of CS events after 1995 were stronger. The negative GPH anomalies over EA were extremely strong, although the area was small, shrinking in northern EA. Therefore, although the intensity of CS events was strong after 1995 , only the northern part of EA was affected. In summary, the wave energy over the North Atlantic mainly spread downstream along the wave train, causing 
the cold air to affect EA by the western path during the period from 1979 to 1995 . In contrast, the energy converged over the northern Ural Mountains and the Kara Sea, causing the cold air to affect the northern part of EA in the northern path during the period from 1996 to 2017. The difference between the two periods was mainly reflected by the perturbation anomalies over the high latitudes and polar region. This result leads us to speculate that Arctic sea ice may be one of the reasons causing this phenomenon.

\section{Relationship between the CS path and winter Arctic sea ice}

The analysis above showed that obvious differences occurred in the circulation structure and energy transfer over the polar regions between the two periods, especially over Novaya Zembla. Previous studies have revealed that Arctic sea ice is considered an important signal reflecting the polar climate and has a significant impact on the winter climate of EA (Tang et al. 2013; Kug et al. 2015; Fan et al. 2018; Dai et al. 2019; Ji and Fan 2019). As shown in Fig. 8a, Arctic SIC has a high correlation with the paths of CSs, especially in the Barents Sea. We selected this area as the key region $\left(75^{\circ}-80^{\circ} \mathrm{N}\right.$, $\left.15^{\circ}-65^{\circ} \mathrm{E}\right)$ and used the winter sea ice in this paper. Figure $8 \mathrm{~b}$ also indicates that the sea ice in the key region has the most obvious difference between the two periods, with a rapid decline after 1995 (Inoue et al. 2012; Wang et al. 2015).

However, the correlation between the two phenomena does not mean that there is a causal relationship between them. Two independent individuals affected by the same external factor often have a strong correlation, although a causal relationship may not exist. Therefore, we introduced Liang-Kleeman (L-K) information flow theory (Liang 2014; Stips et al. 2016; Hagan et al. 2019) to confirm the causal relationship between the Barents Sea ice and the CS path. Using this theory, the causal relationship can be determined only by the time series of the two parameters. According to the theory, under the assumption of linear mode, the maximum likelihood estimation form of the information flow from $X_{2}$ to $X_{1}\left(X_{1}\right.$ and $X_{2}$ are two time series) is

$$
T_{2 \rightarrow 1}=\frac{C_{11} C_{12} C_{2, d 1}-C_{12}^{2} C_{1, d 1}}{C_{11}^{2} C_{22}-C_{11} C_{12}^{2}},
$$

where $C_{i j}$ is the covariance of $X_{i}$ and $X_{j}$ and $C_{i, d j}$ is the covariance of $X_{i}$ and $\left\{\left(X_{j, n+1}-X_{j, n}\right) / \delta t\right\}$, with $\delta t$ represents the time interval. According to the L-K theory, causation implies correlation. However, the converse is that correlation does not imply causation. When $\left|T_{2 \rightarrow 1}\right|>0$,
$X_{2}$ is a cause of $X_{1}$; and when $\left|T_{2 \rightarrow 1}\right|=0, X_{2}$ is not the cause of $X_{1}$.

As shown in Figs. $8 \mathrm{c}$ and $8 \mathrm{~d}$, the information flow from the Barents sea ice concentration (BSIC) to $\mathrm{PC} 2$ is positive. The reverse flow, however, is almost zero, which means that changes in Barents Sea ice lead to changes in PC2. In other words, the Barents Sea ice loss is one of the reasons why the CS path changed from western path dominated to northern path dominated.

The regression of the BSIC affected the GPH and horizontal winds at $500 \mathrm{hPa}$, as shown in Fig. 8e. The GPH over the Arctic is significantly negatively correlated with the BSIC. The information flow (Fig. 8f) also reflects that sea ice loss is the cause of the change in GPH. From 1979 to 1995, the BSIC was high, resulting in negative GPH anomalies over the polar region and strong westerly wind in middle to high latitudes. In contrast, the GPH anomalies over the polar region became positive after 1995, which reduced the ability of the polar vortex to restrain the cold air. The cold air was easy to split southward (Gong and Wang 1999; Rigor et al. 2000; Thompson and Wallace 2001), forming the CSs in the northern path.

Figure 9 reveals the corresponding relationship between the BSIC and GPH anomalies over the polar region from a dynamic perspective using three-dimensional Plumb's WAF. The zonal vertical section of Plumb's WAF was averaged from $75^{\circ}$ to $80^{\circ} \mathrm{N}$. Before 1995 , the WAF spread upward over the Barents Sea, and its horizontal component spread to the polar region under $500 \mathrm{hPa}$. The WAF spread upward and was weak over the Kara Sea, and its meridional component was transported in the lower latitude direction from the surface to the stratosphere. East of $90^{\circ} \mathrm{E}$, the vertical flux propagated downward, and the meridional component spread to higher latitudes. Compared with the 1979 to 1995 period, the upward WAF over the Barents Sea increased after 1995, and its meridional component propagated to the south. The meridional component of the WAF transported to higher latitudes from the Kara Sea increased. These patterns resulted in positive GPH anomalies over the polar region after 1995, and they extended southward over the Ural Mountains and shrank in higher latitudes in Europe and Siberia, making northern path CS events more likely to occur. Recently, Luo et al. (2018, 2019a,b) carried out indepth studies on the dynamic mechanism of Eurasian winter blocking circulation caused by sea ice melting in the Barents Sea by using the potential vorticity theory and made a series of achievements (Luo et al. 2019a), providing strong evidence for the viewpoint of this paper. 

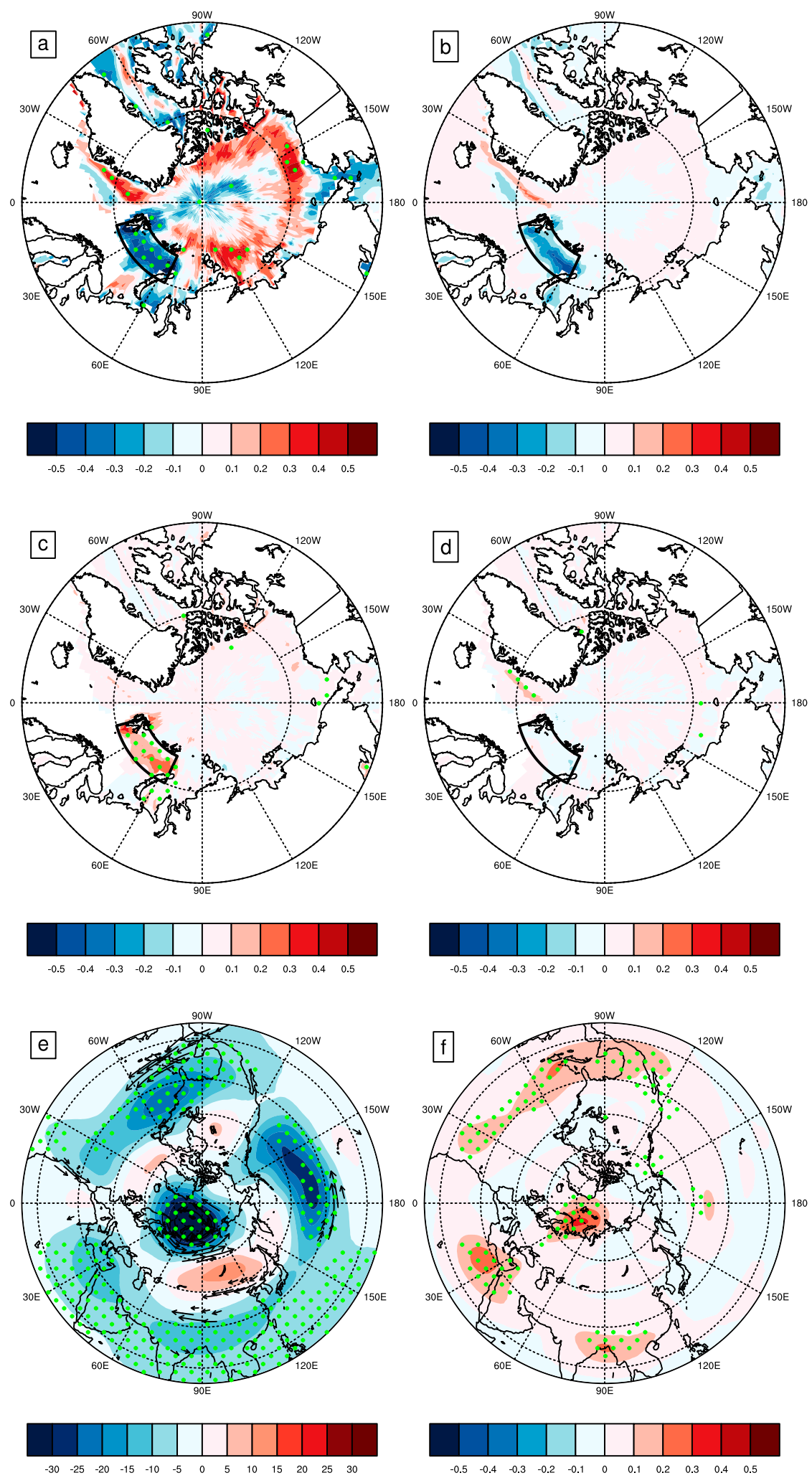

FIG. 8. (a) Correlation coefficients between the Arctic sea ice concentration and PC2. (b) Differences in the Arctic sea ice concentrations before and after 1995. (c),(d) Information flow between PC2 and SIC: $T_{\mathrm{SIC} \rightarrow \mathrm{PC} 2}$ and $T_{\mathrm{PC} 2 \rightarrow \mathrm{SIC}}$, respectively. (e) Regression of the 

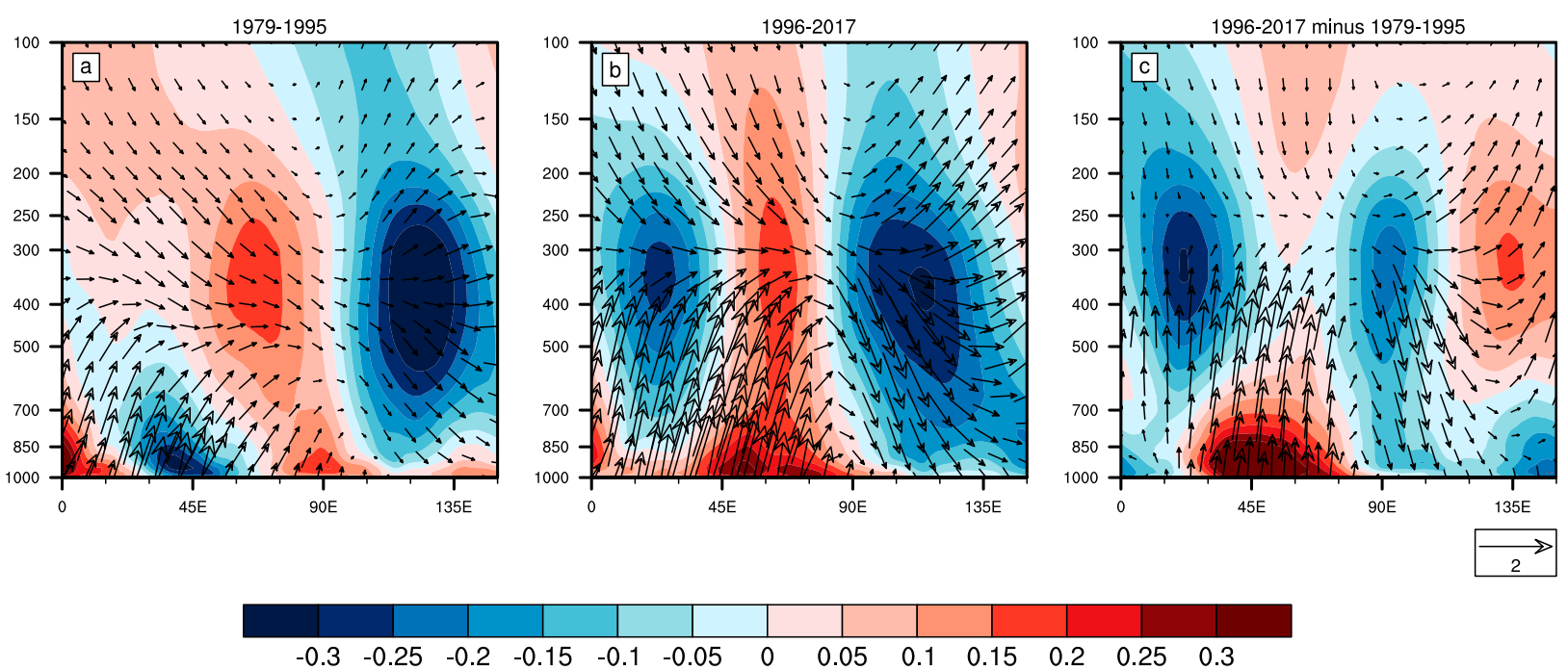

FIG. 9. Composite anomalies of three-dimensional Plumb's WAF averaged from $75^{\circ}$ to $80^{\circ} \mathrm{N}$ (vectors indicate vertical and latitudinal components; shading indicates the meridional component; positive values indicate southward) in winter during (a) 1979 to 1995 and (b) 1996 to 2017, and (c) the difference between these two periods. The vertical component is amplified 150 times.

\section{Numerical simulation results}

To verify whether the interdecadal variation in CS event paths is related to winter BSIC, high Barents sea ice concentration (HBSIC) and low Barents sea ice concentration (LBSIC) experiments with CAM 5.3 were conducted. The detailed scheme is presented in Table 1. Each simulation contained five members and was run for 32 years. We used the last 30 years of the ensemble simulations as the analytical data of each experiment in this study. The HBSIC and LBSIC experiments represent respectively the periods 1979 to 1995 and 1996 to 2017 and the mean winter SIC during the relevant period in the key region $\left(15^{\circ}-65^{\circ} \mathrm{E}, 75^{\circ}-80^{\circ} \mathrm{N}\right)$ is applied, while other regions are the climatological mean (1979 to 2017). In other seasons, the global values are climatological SIC. The global SSTs in these two simulations are both climatological. Therefore, the only difference between the forcing conditions of the two experiments is the winter BSIC.

The simulated frequency and intensity of CS events are shown in Fig. 10. In total, $148 \mathrm{CS}$ events occurred in the HBSIC, with a mean intensity of $-6.9 \mathrm{~K}$, and $130 \mathrm{CS}$ events occurred in the LBSIC, with a mean intensity of $-7.6 \mathrm{~K}$. The mean intensity of CS events in the LBSIC experiment was slightly stronger than that in the HBSIC experiment. The difference in intensity between the two experiments was over 0.5 times the standard deviation. This result is consistent with the findings revealed by the reanalysis results.

Similar to section 3, we synthesized the circulation of CS events in two simulations (Fig. 11). At day -4 relative to the CS outbreak in the HBSIC, significant positive GPH anomalies were observed over the Ural Mountains and negative GPH anomalies were observed over the Mongolian Plateau at 850 and $500 \mathrm{hPa}$. Two days before the CS events occurred, the positive GPH anomalies over the Ural Mountains strengthened and pushed the negative GPH anomalies over EA to the southeast. At the same time, positive GPH anomalies appeared over Japan, forming a zonal wave train structure of positivenegative-positive. When CS events occur, EA is controlled by negative GPH anomalies. Compared with the observed results, the wave train structure in the numerical simulation is more obvious and can reflect the development and eastward movement of a CS process. In the LBSIC, the zonal wave train disappears and is replaced by a blocking structure. Compared with HBSIC, the LBSIC results show that the positive GPH anomalies over the polar region are stronger and extend eastward, while the positive GPH anomalies over the east Pacific

winter GPH (shading) and wind field (vectors; only significant values at the $95 \%$ confidence level are shown) at $500 \mathrm{hPa}$ into the key region of the Barents Sea ice. (f) Information flow between BSIC and winter $\mathrm{GPH}$ at $500 \mathrm{hPa}: T_{\mathrm{BSIC} \rightarrow \mathrm{GPH}}$. Green dots are significant at the $95 \%$ confidence level. The solid box $\left(75^{\circ}-80^{\circ} \mathrm{N}, 15^{\circ}-65^{\circ} \mathrm{E}\right)$ is the key region. 
TABLE 1. Descriptions of numerical simulations using the CAM5.3 atmospheric model.

\begin{tabular}{|c|c|c|c|}
\hline Experiment & Members & Years & Description \\
\hline HBSIC & 5 & 32 & $\begin{array}{l}\text { In each winter, the sea ice in the } \\
\text { key region }\left(75^{\circ}-80^{\circ} \mathrm{N}, 15^{\circ}-\right. \\
\left.65^{\circ} \mathrm{E}\right) \text { is the winter sea ice mean } \\
\text { from } 1979 \text { to } 1995 \text {, while that of } \\
\text { the other regions is the clima- } \\
\text { tological mean ( } 1979 \text { to } 2017) \text {. } \\
\text { In other seasons, the global } \\
\text { values are climatological } \\
\text { mean SIC. }\end{array}$ \\
\hline LBSIC & 5 & 32 & $\begin{array}{l}\text { As in HBSIC, except the winter } \\
\text { SIC in the key region is the } \\
\text { mean from } 1996 \text { to } 2017 \text {. }\end{array}$ \\
\hline
\end{tabular}

Ocean are insignificant. The negative GPH anomaly center moves southward from day -4 to day 0 . This blocking structure makes it easier to form a northern path CS. This result is consistent with the results of the reanalysis data (Fig. 5).

We also analyzed the dynamic differences between the results of the two simulations (Fig. 12). The HBSIC results show that the occurrence of CS events is closely related to the global wave train in middle and high latitudes. From day -4 to day 0 , the WAF over the North Atlantic spreads westward, leading to positive GPH anomalies over the Ural Mountains. These anomalies further develop downstream, guiding the zonal propagation of cold air from the North Atlantic to EA.
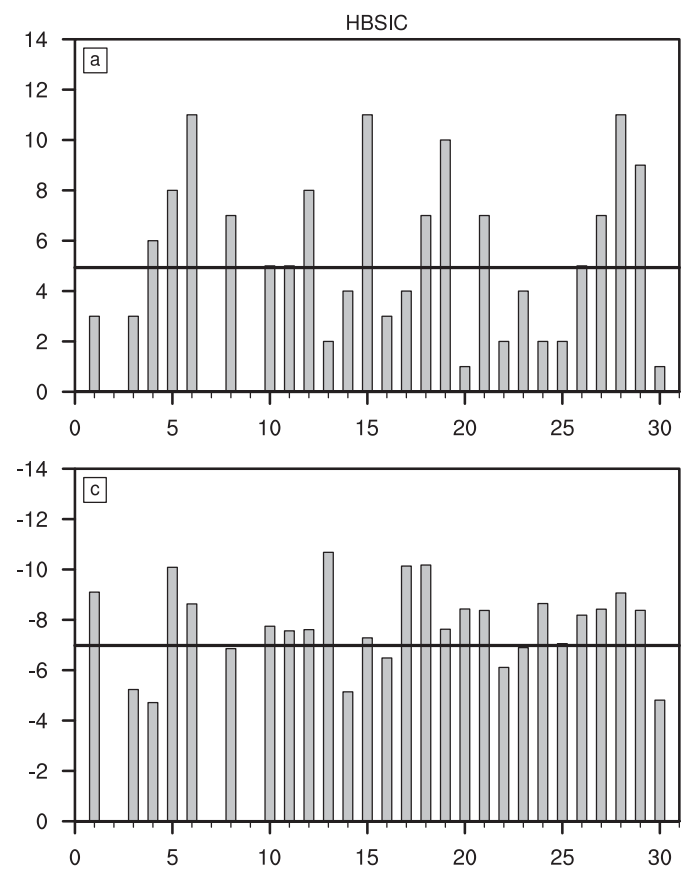

Compared with the observed results (Fig. 7), the WAF in HBSIC further propagates eastward, resulting in significant positive GPH anomalies over the northwestern Pacific Ocean. On the day of the CS outbreak, the anomalies of WAF and GPH over the Pacific Ocean in the HBSIC are stronger and broader than those in the observed results. In the LBSIC, the GPH anomalies over the Ural Mountains extend more northward and eastward compared with the HBSIC experiments and form a blocking structure with negative anomalies over EA. Wave energy converges over the Kara Sea and spreads southeastward, guiding cold air to invade EA. The simulation results show that there are significant negative GPH anomalies over the northwestern Pacific Ocean accompanied by abnormal WAF, which is different from the observed results. This difference may be due to the use of the climatology of sea ice concentration outside key regions in the simulations and its effects on atmospheric circulation. In summary, the features of atmospheric circulation and dynamic processes related to CS events in the HBSIC and LBSIC numerical experiments are consistent with the observed results, indicating that BSIC is an important factor affecting the paths of CSs in EA.

\section{Summary and discussion}

The winter CS events in EA from 1979 to 2017 were counted, and $301 \mathrm{CS}$ events were selected for research
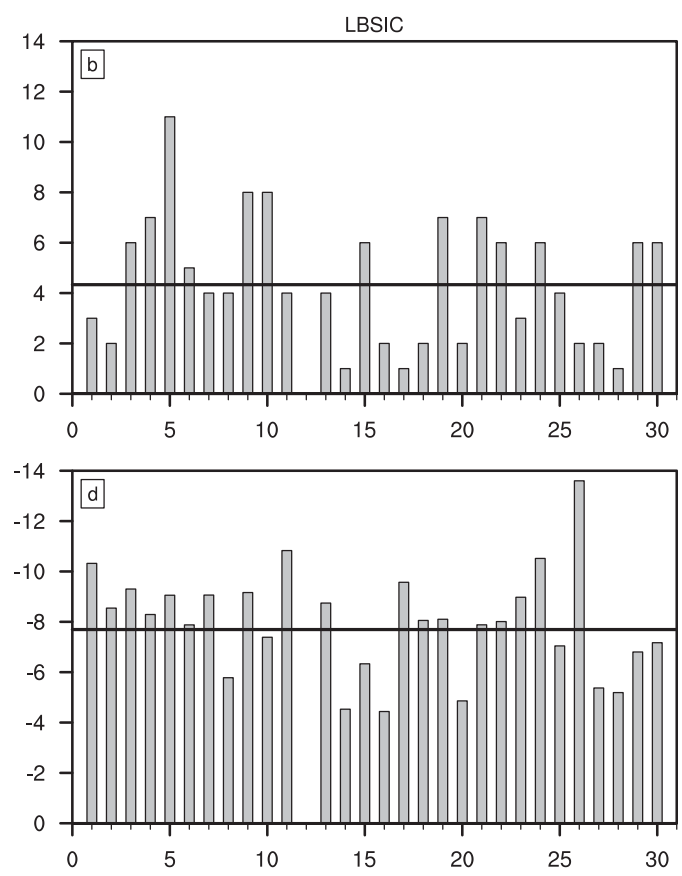

FIG. 10. The simulated (a) frequency and (c) intensity of CS events for HBSIC. (b), (d) As in (a) and (c), but for LBSIC. Thick solid lines represent the mean value. 

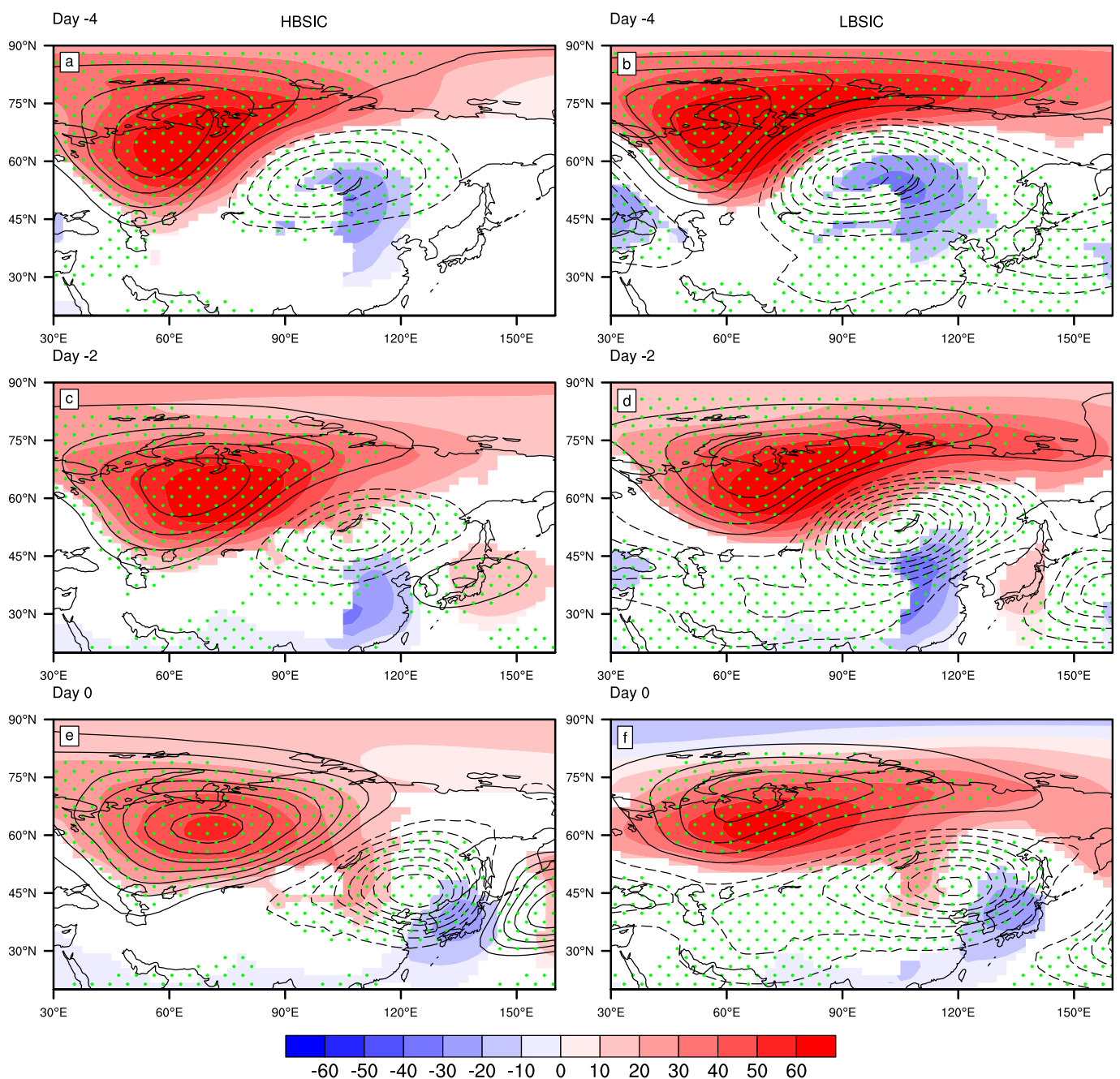

FIG. 11. As in Fig. 5, but for (a),(c),(e) HBSIC and (b),(d),(f) LBSIC.

using ERA-Interim data. FLEXPART was used to track the paths of $301 \mathrm{CS}$ events, and KDE was used to calculate the probability density distribution of the paths. The intensity of CS events demonstrated an interdecadal variation in 1995, transitioning from weak to strong. Before 1995, CS events were more likely to occur with the western path, and cold air invaded EA by the western path from Europe and the North Atlantic. After 1996, northern path CSs became dominant, and cold air invaded EA by the northern path from the areas near Novaya Zembla and the northern Siberia.

By compositing the circulation 4 days before the CS outbreak in 1979 to 1995 and 1996 to 2017, the results showed that the circulation from day -4 to day 0 relative to the CS outbreak mainly had zonal wave train structures from 1979 to 1995. There were positive GPH anomalies over the Ural Mountains and the northwestern Pacific and negative GPH anomalies over EA. WAF anomalies over the North Atlantic spread eastward, causing the wave train to move eastward and develop. These changes would cause the cold air from the North Atlantic and Europe to invade EA. From 1979 to 95, the circulation of the CSs mainly demonstrated a blocking structure. Compared to the period 1979 to 1995, the positive GPH anomalies over the Ural Mountains were more northerly and expanded eastward, forming a blocking structure with negative GPH anomalies over EA. In this period, on day -4 of a CS, the anomalies of WAF converged over the Norwegian Sea and spread eastward, causing the GPH anomalies to strengthen over the Ural Mountains and the polar region; then, the anomalies spread southward on day 0 of the CS, causing the northern path CS in EA.

Further analysis found that BSIC had a significant impact on the CS paths in EA (Fig. 13). When the BSIC was high (low), cold air tended to move from the west 

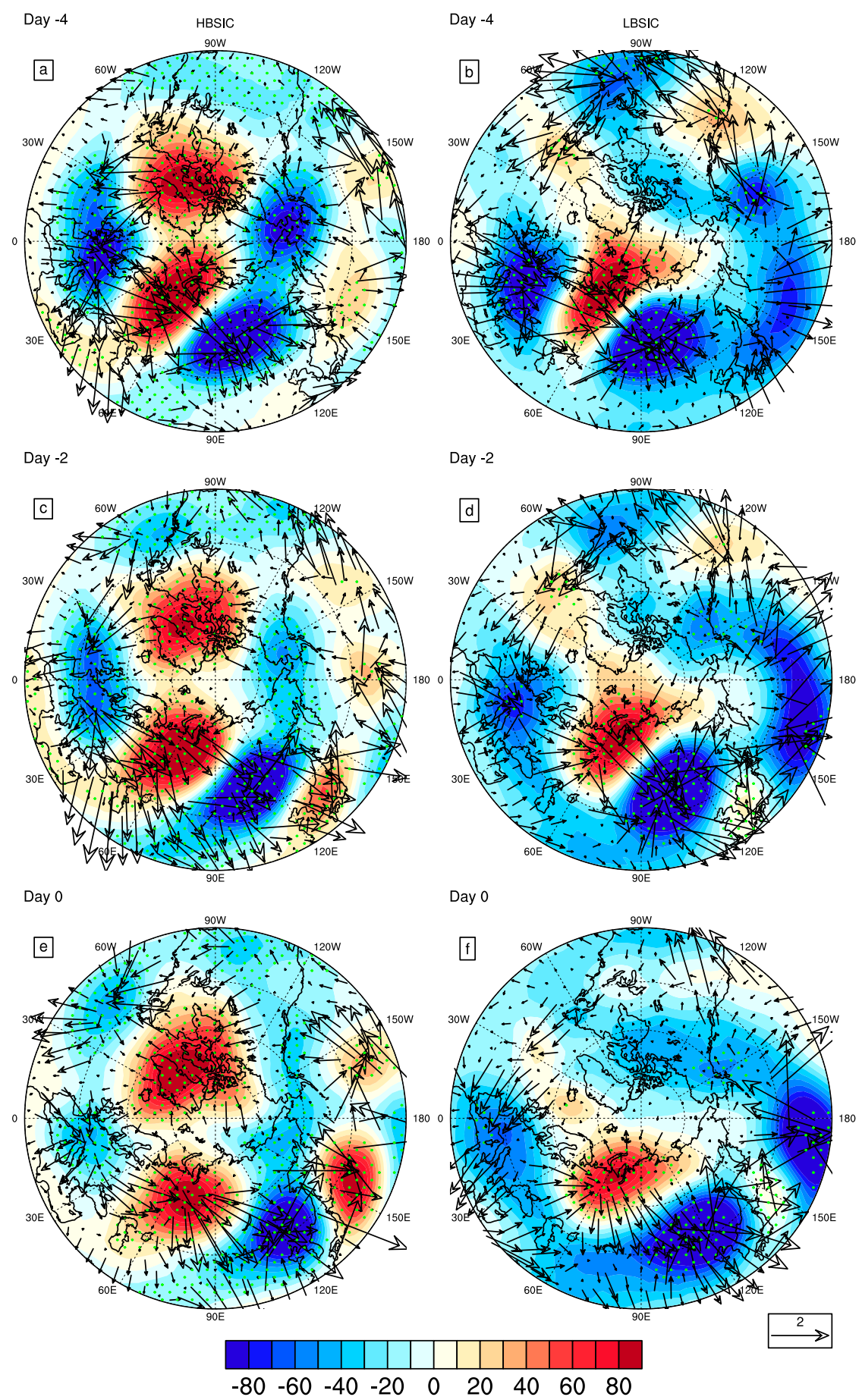

FIG. 12. As in Fig. 7, but for (a),(c),(e) HBSIC and (b),(d),(f) LBSIC.

(north). Before 1995, the BSIC was significantly high, and the upward wave energy was relatively weak, causing a strong polar vortex and strong west wind and increasing the likelihood of forming zonal wave train CS events. From 1996 to 2017, global warming led to the rapid melting of Arctic sea ice, especially in the Barents Sea. The upward wave flux over the Barents Sea was strong and transported to lower latitudes, resulting in positive GPH anomalies over the polar region and negative GPH anomalies over EA, which increased the likelihood of the northern path CS events. We further verified these conclusions using numerical simulations. 


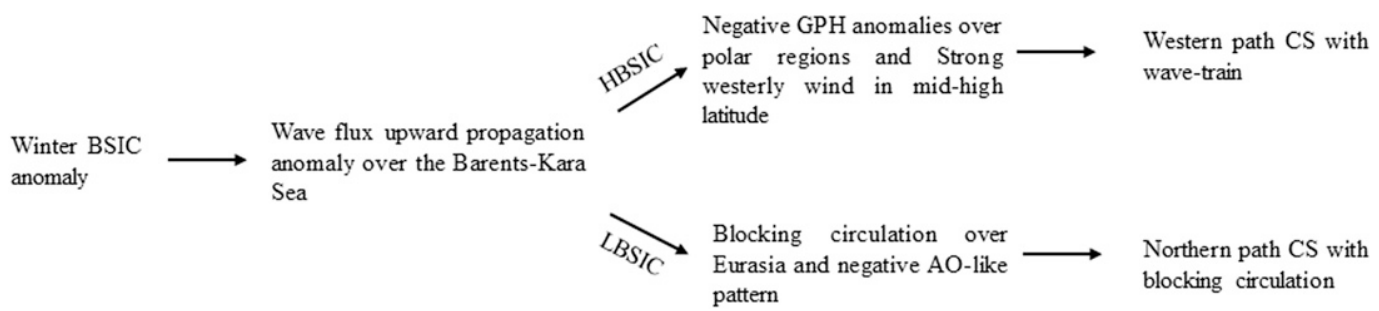

FIG. 13. Possible mechanism of the linkage between the winter BSIC and the winter CS path in EA.

In the HBSIC (LBSIC), the intensity of the CS was weak (strong), and the paths of CSs were dominated by the western path (northern path). It should be noted that the numerical experiments in the present study are idealized compared with existing simulations (Ogawa et al. 2018).

As an external forcing factor, sea ice provides a positive contribution to the interdecadal variation of the dominant mode of the CS path, although we have not yet quantitatively analyzed the contribution. More detailed mechanisms and the combined effects of multiple factors still need further study. At the same time, the change of Arctic sea ice is also affected by other factors, such as the North Atlantic SST anomalies. This feedback relationship needs a more in-depth study. The AMO phase shifted in the mid-1990s (Sutton and Hodson 2007). Wang et al. (2009) indicated that the warm phase of the AMO resulted in low SAT in northern EA in winter. Thus, further research is needed to determine whether the shift in the AMO phase contributes to the decadal variation in the CS paths.

Acknowledgments. This research is supported by the National Natural Science Foundation of China (41575085 and 41430528) and the National Key Research and Development Program of China (2017YFA0603804).

\section{REFERENCE}

Alexander, L. V., and Coauthors, 2006: Global observed changes in daily climate extremes of temperature and precipitation. J. Geophys. Res., 111, D05109, https://doi.org/10.1029/ 2005JD006290.

Barnes, E. A., and J. A. Screen, 2015: The impact of Arctic warming on the midlatitude jet- stream: Can it? Has it? Will it? Wiley Interdiscip. Rev.: Climate Change, 6, 277-286, https:// doi.org/10.1002/WCC.337.

Blackport, R., and J. A. Screen, 2019: Influence of Arctic sea ice loss in autumn compared to that in winter on the atmospheric circulation. Geophys. Res. Lett., 46, 2213-2221, https://doi.org/ 10.1029/2018GL081469.

,$- \ldots$, K. van der Wiel, and B. Richard, 2019: Minimal influence of reduced Arctic sea ice on coincident cold winters in mid-latitudes. Nat. Climate Change, 9, 697-704, https://doi.org/ 10.1038/s41558-019-0551-4.

Cai, B., G. Zeng, G. Zhang, and Z. Li, 2019: Autumn cold surge paths over North China and the associated atmospheric circulation. Atmosphere, 10, 134, https://doi.org/10.3390/ atmos10030134.

Chan, J., and C. Li, 2004: The East Asia winter monsoon. East Asian Monsoon, C.-P. Chang, Ed., World Scientific, 54-106.

Chen, H., L. Liu, and Y. Zhu, 2013: Possible linkage between winter extreme low temperature events over China and synoptic-scale transient wave activity (in Chinese). Sci. China Earth Sci., 56, 1266-1280, https://doi.org/10.1007/s11430-0124442-z.

Chen, T., 2002: A North Pacific short-wave train during the extreme phases of ENSO. J. Climate, 15, 2359-2376, https:// doi.org/10.1175/1520-0442(2002)015<2359:ANPSWT>2.0. $\mathrm{CO} ; 2$.

— W. Wuang, and J. Yoon, 2004: Interannual variation of the East Asian cold surge activity. J. Climate, 17, 401-413, https:// doi.org/10.1175/1520-0442(2004)017<0401:IVOTEA >2.0. $\mathrm{CO} ; 2$.

Chen, W., S. Yang, and R.-H. Huang, 2005: Relationship between stationary planetary wave activity and the East Asian winter monsoon. J. Geophys. Res., 110, D14110, https://doi.org/ 10.1029/2004JD005669.

Choi, Y.-S., C.-H. Ho, D.-Y. Gong, J.-H. Jeong, and T.-W. Park, 2009: Adaptive change in intra-winter distribution of relatively cold events to East Asian warming. Terr. Atmos. Oceanic. Sci., 20, 807-816, https://doi.org/10.3319/TAO.2008.11.20.01(A).

Dai, H., K. Fan, and J. Liu, 2019: Month-to-month variability of winter temperature over Northeast China linked to sea ice over the Davis Strait-Baffin Bay and the Barents-Kara Sea. J. Climate, 32, 6365-6384, https://doi.org/10.1175/JCLI-D18-0804.1.

Dee, D. P., and Coauthors, 2011: The ERA-Interim Reanalysis: Configuration and performance of the data assimilation system. Quart. J. Roy. Meteor. Soc., 137, 553-597, https://doi.org/ 10.1002/qj.828.

Ding, Y., 1990: Build-up, air mass transformation and propagation of Siberian high and its relations to cold wave in East Asia. Meteor. Atmos. Phys., 44, 281-292, https://doi.org/10.1007/ BF01026822.

Fan, K., Z. Xie, H. Wang, Z. Xu, and J. Liu, 2018: Frequency of spring dust weather in North China linked to sea ice variability in the Barents Sea. Climate Dyn., 51, 4439-4450, https:// doi.org/10.1007/s00382-016-3515-7.

Francis, J., and S. Vavrus, 2012: Evidence linking Arctic amplification to extreme weather in mid-latitudes. Geophys. Res. Lett., 39, L06801, https://doi.org/10.1029/2012GL051000.

Gao, X., Z. Zhao, and F. Giorgi, 2002: Changes of extreme events in regional climate simulations over East Asia. Adv. Atmos. Sci., 19, 927-942, https://doi.org/10.1007/s00376-002-0056-2.

Gao, Y., and Coauthors, 2014: Arctic sea ice and Eurasian climate: A review. Adv. Atmos. Sci., 32, 92-114, https://doi.org/10.1007/ s00376-014-0009-6. 
Gong, D., and S. Wang, 1999: Definition of Antarctic Oscillation index. Geophys. Res. Lett., 26, 459-462, https://doi.org/ 10.1029/1999GL900003.

Hagan, D. F. T., G. Wang, X. Liang, and H. A. Dolman, 2019: A time-varying causality formalism based on the LiangKleeman information flow for analyzing directed interactions in non-stationary climate systems. J. Climate, 32, 7521-7537, https://doi.org/10.1175/JCLI-D-18-0881.1.

Heo, J.-W., C.-H. Ho, T.-W. Park, W. Choi, J.-H. Jeong, and J. Kim, 2018: Changes in cold surge occurrence over East Asia in the future: Role of thermal structure. Atmosphere, 9, 222, https://doi.org/10.3390/atmos9060222.

Honda, M., J. Inoue, and S. Yamane, 2009: Influence of low Arctic sea-ice minima on anomalously cold Eurasian winters. Geophys. Res. Lett., 36, L08707, https://doi.org/10.1029/ 2008 GL037079.

Huang, D.-Q., A.-G. Dai, B. Yang, P. Yan, J. Zhu, and Y.-C. Zhang, 2019: Contributions of different combinations of the IPO and AMO to recent changes in winter East Asian jets. $J$. Climate, 32, 1607-1626, https://doi.org/10.1175/JCLI-D-180218.1.

Inoue, J., M. E. Hori, and K. Takaya, 2012: The role of Barents sea ice in the wintertime cyclone track and emergence of a warmArctic cold-Siberian anomaly. J. Climate, 25, 2561-2568, https://doi.org/10.1175/JCLI-D-11-00449.1.

IPCC, 2007: Climate Change 2007: The Physical Science Basis. S. Solomon et al., Eds., Cambridge University Press, 996 pp. , 2013: Climate Change 2013: The Physical Science Basis. T. F. Stocker et al., Eds., Cambridge University Press, 1535 pp., https://doi.org/10.1017/CBO9781107415324.

Jeong, J.-H., and C.-H. Ho, 2005: Changes in occurrence of cold surges over East Asia in associated with Arctic Oscillation. Geophys. Res. Lett., 32, L14704, https://doi.org/10.1029/ 2005GL023024.

Ji, L., and K. Fan, 2019: Interannual linkage between wintertime sea-ice cover variability over the Barents Sea and springtime vegetation over Eurasia. Climate Dyn., 53, 5637-5652, https:// doi.org/10.1007/s00382-019-04884-0.

Kim, B.-M., S.-W. Son, S.-K. Min, J.-H. Jeong, S.-J. Kim, X. Zhang, T. Shim, and J.-H. Yoon, 2014: Weakening of the stratospheric polar vortex by Arctic sea-ice loss. Nat. Commun., 5, 4646, https://doi.org/10.1038/ncomms5646.

Kug, J., J. Jeong, Y. Jang, B. Kim, C. K. Folland, S. Min, and S. Son, 2015: Two distinct influences of Arctic warming on cold winters over North America and East Asia. Nat. Geosci., 8, 759762, https://doi.org/10.1038/ngeo2517.

Li, F., and H. Wang, 2012: Relationship between Bering Sea ice cover and East Asian winter monsoon year-to-year variations. Adv. Atmos. Sci., 30, 48-56, https://doi.org/10.1007/s00376012-2071-2.

Li, X., 1955: A study of cold waves in East Asia. Offprints of Scientific Works in Modern China-Meteorology (1919-1949), Science Press, 35-117.

Liang, X. S., 2014: Unraveling the cause-effect relation between time series. Phys. Rev., 90, 052150, https://doi.org/10.1103/ PHYSREVE.90.052150.

Liu, J., J. Curry, H. Wang, M. Song, and R. Horton, 2012: Impact of declining Arctic sea ice on winter snowfall. Proc. Natl. Acad. Sci. USA, 109, 4074-4079, https://doi.org/10.1073/ pnas.1114910109.

Lorenz, E. N., 1956: Empirical orthogonal functions and statistical weather prediction. MIT Department of Meteorology, Statistical Forecasting Project Scientific Rep. 1, 49 pp., https://
eapsweb.mit.edu/sites/default/files/Empirical_Orthogonal_ Functions_1956.pdf.

Luo, D., X. Chen, A. Dai, and I. Simmonds, 2018: Changes in atmospheric blocking circulations linked with winter Artic warming: A new perspective. J. Climate, 31, 7661-7678, https:// doi.org/10.1175/JCLI-D-18-0040.1.

— W. Zhang, L. Zhong, and A. Dai, 2019a: A nonlinear theory of atmospheric blocking: A potential vorticity gradient view. $J$. Atmos. Sci., 76, 2399-2427, https://doi.org/10.1175/JAS-D-180324.1.

- X. Chen, J. Overland, I. Simmonds, Y. Wu, and P. Zhang, 2019b: Weakened potential vorticity barrier linked to recent winter Arctic sea ice loss and midlatitude cold extremes. J. Climate, 32, 4235-4261, https://doi.org/10.1175/JCLI-D-18-0449.1.

Makshtas, A., and E. Andreas, 1991: The Heat Budget of Arctic Ice in the Winter. International Glaciological Society, $77 \mathrm{pp}$.

McCusker, K., J. Fyfe, and M. Sigmond, 2016: Twenty-five winters of unexpected Eurasian cooling unlikely due to Arctic sea ice loss Nat. Geosci., 9, 838-842, https://doi.org/10.1038/ngeo2820.

Mori, M., Y. Kosaka, M. Watanabe, H. Nakamura, and M. Kimoto, 2019a: A reconciled estimate of the influence of Arctic sea-ice loss on recent Eurasian cooling. Nat. Climate Change, 9, 123129, https://doi.org/10.1038/s41558-018-0379-3.

,,,--- B. Taguchi, H. Nakamura, and M. Kimoto, 2019b: Reply to: Is sea-ice-driven Eurasian cooling too weak in models? Nat. Climate Change, 9, 937-939, https://doi.org/ 10.1038/s41558-019-0636-0.

Neale, R. B., and Coauthors, 2012: Description of the NCAR Community Atmosphere Model (CAM5.0). NCAR Tech. Note NCAR/TN-486+STR, 274 pp., www.cesm.ucar.edu/ models/cesm1.0/cam/docs/description/cam5_desc.pdf.

Ogawa, F., and Coauthors, 2018: Evaluating impacts of recent Arctic sea ice loss on the Northern Hemisphere winter climate change. Geophys. Res. Lett., 45, 3255-3263, https://doi.org/ 10.1002/2017GL076502.

Ogi, M., K. Yamazaki, and J. Wallace, 2010: Influence of winter and summer surface wind anomalies on summer Arctic sea ice extent. Geophys. Res. Lett., 37, L07701, https://doi.org/ 10.1029/2009GL042356.

Park, T.-W., and Y. Deng, 2013: A synoptic and dynamical characterization of wave-train and blocking cold surge over East Asia. Climate Dyn., 43, 753-770, https://doi.org/10.1007/ s00382-013-1817-6.

- C.-H. Ho, and S. Yang, 2011a: Relationship between the Arctic Oscillation and cold surges over East Asia. J. Climate, 24, 68-83, https://doi.org/10.1175/2010JCLI3529.1.

— S.-J. Jeong, Y.-S. Choi, S. K. Park, and C.-K. Song, 2011b: Different characteristics of cold day and cold surge frequency over East Asia in a global warming situation. J. Geophys. Res., 116, D12118, https://doi.org/10.1029/2010JD015369.

Parzen, E., 1962: On estimation of a probability density function and mode. Ann. Math. Stat., 33, 1065-1076, https://doi.org/ 10.1214/aoms/1177704472.

Petoukhov, V., and V. Semenov, 2010: A link between reduced Barent-Kara sea ice and cold winter extremes over northern continents. J. Geophys. Res., 115, D21111, https://doi.org/ 10.1029/2009JD013568

Pisso, I., and Coauthors, 2019: The Lagrangian particle dispersion model FLEXPART version 10.4. Geosci. Model Dev., 12, 4955-4997, https://doi.org/10.5194/gmd-12-4955-2019.

Plumb, R. A., 1985: On the three-dimensional propagation of stationary waves. J. Atmos. Sci., 42, 217-229, https://doi.org/10.1175/ 1520-0469(1985)042<0217:OTTDPO >2.0.CO;2. 
Proshutinsky, A., and M. Johnson, 1997: Two circulation regimes of the wind driven Arctic Ocean. J. Geophys. Res., 102, 12493 12 514, https://doi.org/10.1029/97JC00738.

Rayner, N. A., D. E. Parker, E. B. Horton, C. K. Folland, L. V. Alexander, D. P. Rowell, E. C. Kent, and A. Kaplan, 2003: Global analyses of sea surface temperature, sea ice, and night marine air temperature since the late nineteenth century. J. Geophys. Res., 108, 4407, https://doi.org/10.1029/ 2002JD002670.

Rigor, I. G., R. L. Colony, and S. Martin, 2000: Variations in surface air temperature observations in the Arctic, 1979-97. J. Climate, 13, 896-914, https://doi.org/10.1175/1520-0442(2000) $013<0896$ :VISATO $>2.0 . \mathrm{CO} ; 2$.

Rosenblatt, M., 1956: Remarks on some nonparametric estimates of a density function. Ann. Math. Stat., 27, 832-837, https:// doi.org/10.1214/aoms/1177728190.

Ryoo, S.-B., W.-T. Kwon, and J.-G. Jhun, 2005: Surface and upperlevel features associated with wintertime cold surge outbreaks in South Korea. Adv. Atmos. Sci., 22, 509-524, https://doi.org/ 10.1007/BF02918484.

Screen, J. A., and I. Simmonds, 2010: The central role of diminishing sea ice in the recent Arctic temperature amplification. Nature, 464, 1334-1337, https://doi.org/10.1038/nature09051.

_ sea ice on coincident cold winters in mid-latitudes. Nat. Climate Change, 9, 697-704, https://doi.org/10.1038/s41558019-0551-4.

$\ldots$, and _ 2019b: Is sea-ice-driven Eurasian cooling too weak in models? Nat. Climate Change, 9, 934-936, https://doi.org/ 10.1038/s41558-019-0635-1.

Serreze, M. C., M. M. Holland, and J. Stroeve, 2007: Perspectives on the Arctic's shrinking sea-ice cover. Science, 315, 15331536, https://doi.org/10.1126/science.1139426.

Shi, C., X. Jin, and R. Liu, 2017: The differences in characteristics and applicability among three types of Rossby wave activity flux in atmospheric dynamics (in Chinese). Trans. Atmos. Sci., 40, 850 855, https://doi.org/10.13878/j.cnki.dqkxxb.20161023012.

Stips, A., D. Macias, C. Coughlan, E. Garcia-Gorriz, and X. Liang, 2016: On the causal structure between $\mathrm{CO}_{2}$ and global temperature. Sci. Rep., 6, 21691, https://doi.org/10.1038/srep21691.

Stohl, A., 1998: Computation, accuracy and applications of trajectories-A review and bibliography. Atmos. Environ., 32, 947-966, https://doi.org/10.1016/S1352-2310(97)00457-3.

Sun, L., J. Perlwitz, and M. Hoerling, 2016: What caused the recent "warm Arctic, cold continents" trend pattern in winter temperatures? Geophys. Res. Lett., 43, 5345-5352, https://doi.org/ 10.1002/2016GL069024.

Sutton, R., and D. Hodson, 2007: Climate response to basin-scale warming and cooling of the North Atlantic Ocean. J. Climate, 20, 891-907, https://doi.org/10.1175/JCLI4038.1.

Tang, Q., X. Zhang, X. Yang, and J. A. Francis, 2013: Cold winter extremes in northern continents linked to Arctic sea ice loss. Environ. Res. Lett., 8, 014036, https://doi.org/10.1088/17489326/8/1/014036.

Tao, S., 1957: A study of activities of cold airs in East Asian winter. Handbook of Short-Term Forecast, China Meteorological Administration, Eds., Meteorology Press, 60-92.
Thompson, D. W. J., and J. M. Wallace, 2001: Regional climate impacts of the Northern Hemisphere annular mode. Science, 293, 85-89, https://doi.org/10.1126/science.1058958.

Thorndike, A. S., and R. Colony, 1982: Sea ice motion in response to geostrophic winds. J. Geophys. Res., 87, 5845-5852, https:// doi.org/10.1029/JC087iC08p05845.

Walsh, J. E., A. S. Phillips, D. H. Portis, and W. L. Chapman, 2001: Extreme cold outbreaks in the United States and Europe, 1948-99. J. Climate, 14, 2642-2658, https://doi.org/10.1175/ 1520-0442(2001)014<2642:ECOITU > 2.0.CO;2.

Wang, H., H. P. Chen, and J. P. Liu, 2015: Arctic sea ice decline intensified haze pollution in eastern China. Atmos. Oceanic Sci. Lett., 8, 1-9, https://doi.org/10.3878/AOSL20140081.

Wang, Y., S. Li, and D. Luo, 2009: Seasonal response of Asian monsoonal climate to the Atlantic multidecadal oscillation. J. Geophys. Res., 114, D02112, https://doi.org/10.1029/2008JD010929.

Wang, Z., and Y. Ding, 2006: Climate change of the cold wave frequency of China in the last 53 years and the possible reasons (in Chinese). Chin. J. Atmos. Sci., 30, 1068-1076.

Woo, S.-H., B. Kim, J.-H. Jeong, S. Kim, and G. Lim, 2012: Decadal changes in surface air temperature variability and cold surge characteristics over northeast Asia and their relation with the Arctic Oscillation for the past three decades (1979-2011). $J$. Geophys. Res., 117, 18117, https://doi.org/10.1029/2011JD016929.

$\mathrm{Wu}, \mathrm{B} ., 2017$ : Winter atmospheric circulation anomaly associated with recent Arctic winter warm anomalies. J. Climate, 30, 8469-8479, https://doi.org/10.1175/JCLI-D-17-0175.1.

_ and East Asian winter monsoon. J. Geophys. Res., 29, 1897, https://doi.org/10.1029/2002GL015373.

_, R. Huang, and D. Gao, 1999: Effects of variation of winter sea-ice area in Kara and Barents Seas on East Asian winter monsoon. Acta Meteor. Sin., 13, 141-153.

—, D. Handorf, K. Dethloff, A. Rinke, and A. Hu, 2013: Winter weather patterns over northern Eurasia and Arctic sea ice loss. Mon. Wea. Rev., 141, 3786-3800, https://doi.org/10.1175/ MWR-D-13-00046.1.

_ K. Yang, and J. Francis, 2016: Summer Arctic dipole wind pattern affects the winter Siberian high. Int. J. Climatol., 36, 4187-4201, https://doi.org/10.1002/joc.4623.

Yang, G., Q. Kong, D. Mao, F. Zhang, Z. Kang, and Z. Zong, 2010: Analysis on the long-lasting freezing rain and snowstorm event at the beginning of 2008. Acta Meteor. Sin., 24, 380-396.

Zhang, G., G. Zeng, D. Ni, and G. Zhou, 2016: Decadal shift of autumn drought in Southwest China and its possible causes (in Chinese). Chin. J. Atmos. Sci., 40, 311-323, https://doi.org/ 10.3878/j.issn.1006-9895.1503.14294.

Zhang, Y., K. R. Sperber, and J. S. Boyle, 1997: Climatology and interannual variation of the East Asian winter monsoon: Results from the 1979-95 NCEP/NCAR reanalysis. Mon. Wea. Rev., 125, 2605-2619, https://doi.org/10.1175/15200493(1997)125<2605:CAIVOT > 2.0.CO;2.

Zhao, P., X. Zhang, X. Zhou, M. Ikeda, and Y. Yin, 2004: The sea ice extent anomaly in the North Pacific and its impact on the East Asian summer monsoon rainfall. J. Climate, 17, 34343447, https://doi.org/10.1175/1520-0442(2004)017<3434: TSIEAI $>2.0 . \mathrm{CO} ; 2$. 